\title{
Strategies for stable water splitting via protected photoelectrodes
}

Bae, Dowon; Seger, Brian; Vesborg, Peter Christian Kjærgaard; Hansen, Ole; Chorkendorff, Ib

Published in:

Chemical Society Reviews

Link to article, DOI:

$10.1039 / \mathrm{c} 6 \mathrm{cs} 00918 \mathrm{~b}$

Publication date:

2017

Document Version

Peer reviewed version

Link back to DTU Orbit

Citation (APA):

Bae, D., Seger, B., Vesborg, P. C. K., Hansen, O., \& Chorkendorff, I. (2017). Strategies for stable water splitting via protected photoelectrodes. Chemical Society Reviews, 46(7), 1933-1954.

https://doi.org/10.1039/c6cs00918b

\section{General rights}

Copyright and moral rights for the publications made accessible in the public portal are retained by the authors and/or other copyright owners and it is a condition of accessing publications that users recognise and abide by the legal requirements associated with these rights.

- Users may download and print one copy of any publication from the public portal for the purpose of private study or research.

- You may not further distribute the material or use it for any profit-making activity or commercial gain

- You may freely distribute the URL identifying the publication in the public portal

If you believe that this document breaches copyright please contact us providing details, and we will remove access to the work immediately and investigate your claim. 
Chem. Soc. Rev. 46, 1933-1954 (2017)

DOI: $10.1039 / \mathrm{c} 6 \mathrm{cs} 00918 \mathrm{~b}$

\title{
Strategies for stable water splitting via protected photoelectrodes
}

\author{
Dowon Bae, ${ }^{a}$ Brian Seger, ${ }^{a}$ Peter C.K. Vesborg, ${ }^{a}$ Ole Hansen, ${ }^{b}$ and Ib Chorkendorff ${ }^{\text {* }}$ \\ ${ }^{a}$ Department of Physics, Technical University of Denmark, DK-2800 Kgs. Lyngby, Denmark \\ ${ }^{b}$ Department of Micro- and Nanotechnology, Technical University of Denmark, DK-2800 Kgs. Lyngby, Denmark \\ *Corresponding author: ibchork@fysik.dtu.dk;Tel: +45) 452531 70; Fax: +45) 45932399
}

\begin{abstract}
Photoelectrochemical (PEC) solar-fuel conversion is a promising approach to provide clean and storable-fuel (e.g., hydrogen and methanol) directly from sunlight, water and $\mathrm{CO}_{2}$. However, major challenges still have to be overcome before commercialization can be achieved. One of the largest barriers to overcome is to achieve a stable PEC reaction in either strongly basic or acidic electrolytes without degradation of the semiconductor photoelectrodes. In this work, we discuss fundamental aspects of protection strategies for achieving stable solid/liquid interfaces. We then analyse the charge transfer mechanism through the protection layers for both photoanodes and photocathodes. In addition, we review protection layer approaches and their stabilities for a wide variety of experimental photoelectrodes for water reduction. Finally, we discuss key aspects which should be addressed in continued work on realizing the stable and practical PEC solar water splitting systems.
\end{abstract}




\section{Introduction}

Photoelectrochemical (PEC) water splitting is a promising approach to provide clean and storable chemical fuel (e.g. hydrogen) directly from sunlight, whereas photovoltaic (PV) solar cell technology directly converts solar energy into electricity, which must be consumed immediately or converted to a storable form of energy (e.g., using batteries or capacitors (with limited storage capacity)). The overall PEC water splitting process consists of three parts: (i) light absorption resulting in charge carrier generation, (ii) transportation of charge to the surfaces, and (iii) the utilization of excited photo carriers to drive catalytic reactions at the surfaces. ${ }^{1-3}$ Thus it is essential to transport the photo-generated carriers from a photo-absorber to a solid/liquid interface, where catalytic sites can oxidise or reduce the water. The reductive reaction leads to chemical fuel production, i.e., the hydrogen $\left(\mathrm{H}_{2}\right.$ ) evolution reaction (HER) from $\mathrm{H}^{+}$(in acid) or $\mathrm{H}_{2} \mathrm{O}$ (in base), whereas the oxidative halfreaction produces $\mathrm{O}_{2}$ from $\mathrm{H}_{2} \mathrm{O}$ (in acid) or $\mathrm{OH}^{-}$(in base) (oxygen evolution reaction - OER). ${ }^{3,4}$ The products of the overall reaction may be formed in a single compartment, via suspensions of photocatalyst particles, 5,6 resulting in a system that produces a mixture of chemical products which subsequently should be collected separately to mitigate back reactions..$^{5}$ Alternatively, both oxidation (at the photoanode) and reduction reactions (at the photocathode) can be carried out in separate compartments, such as on wired ${ }^{7}$ or on monolithic photoelectrodes; ${ }^{8}$ which eliminates the need for a separate gas separation step. However, this approach often requires high ionic strength to minimize Ohmic losses and localized pH gradient overpotentials $(\eta)^{9}$ while minimizing product-crossover. Thus it is likely that either strong acid (low $\mathrm{pH}$ ) or alkaline (high $\left.\mathrm{pH}\right)$ conditions are necessary, ${ }^{9,10}$ but such harsh conditions may potentially lead to corrosion of the photoabsorber materials. This work will thus focus on analysing how to protect these photoelectrodes in separate compartments.

To date, there has been tremendous effort put into demonstrating efficient and chemically stable photoelectrodes for both HER and OER at various pHlevels. By characterizing photoanodes and photocathodes independently, the expected performance of an integrated system without an external bias voltage can be directly estimated. The intersection of the overlapped linear sweeping voltammetry (LSV) or cyclic voltammetry (CV) data (see Fig. 1a) for each photocathode/anode indicates the maximum operating current density $\left(J_{O P}\right)$ for the overall water splitting system. Metal oxides are materials that are often stable under water oxidation conditions, and typically provide the necessary band bending to allow a charge separation for 
efficient photo-generated carrier transport in contact with the electrolyte. However, the optical transitions for many of the materials with optimal band gaps for water splitting are usually forbidden d-d transitions, and thus they have very small optical absorption coefficients. ${ }^{11}$ In addition, carriers in metal oxide semiconductor d-bands are known to have poor mobilities, resulting in very short carrier diffusion lengths, ${ }^{11,12}$ which remain a major obstacle to achieve a high solar-to-hydrogen efficiency (STH\%). As shown in Fig. 1, simple combinations of previously demonstrated LSV curves ${ }^{2,13-24}$ from the state-of-the-art photoelectrodes are still inadequate to form any highly efficient tandem water splitting system. In contrast, a combination of experimental low bandgap $\left(E_{g}\right)$ photocathodes with a modelled ideal half-cell ${ }^{25}$ with $E_{g}$ of $1.8 \mathrm{eV}$ results in $J_{O P}$ above $17 \mathrm{~mA} \mathrm{~cm}^{-2}$ which corresponds to solar-to-hydrogen efficiency (STH\%) above 20\% (Note that $J_{O P}$ values were estimated without considering Ohmic-loss between the two photoelectrodes and parasitic optical loss caused by the high $E_{g}$ topcell semiconductor). For instance, a $\mathrm{BiVO}_{4}$-based water splitting device combined with multi-junction a-Si PV cell has shown only a modest efficiency $(4.9 \%)^{26}$ due to low photocurrent output from the $\mathrm{BiVO}_{4}$ photoanode layer. An earth-abundant low-cost iron-oxide (hematite, a- $\mathrm{Fe}_{2} \mathrm{O}_{3}$ ) based photoanode coupled with perovskite solar cell has demonstrated barely above $4 \mathrm{~mA} \mathrm{~cm}^{-2}$ under alkaline condition. ${ }^{27}$ The opposite case of high $E_{g}$ photocathodes ${ }^{16,18,19}$ with low $E_{g}$ photoanodes ${ }^{14,21,24}$ (Fig. 1b) shows essentially the same picture: The only pair of experimentally demonstrated photoelectrodes which results in a meaningful $J_{O P}\left(\sim 1.4 \mathrm{~mA} \mathrm{~cm}^{-2}\right)$ is a nanowire $\mathrm{p}$-GaP-based photocathode ${ }^{19}$ in combination with a buried $n p^{+}$-junction GaAs-based photoanode. ${ }^{14}$ Both figures (1a and $1 \mathrm{~b}$ ) indicate that use of proven high-performance solar cell materials with chargeseparation structures (e.g., a buried junction), and appropriate corresponding protective materials are essential, in order to obtain a true practical and simple tandem PEC water splitting system for solar-fuel generation. Recent progress in nitrogen-doped $\mathrm{BiVO}_{4}$ with the band-gap reduced by 0.2 eV over the pure $\mathrm{BiVO}_{4}{ }^{22}$ brightened the prospects for practical application to PEC water splitting, but it still has a large bandgap ( $2.27 \mathrm{eV})$, which means it will never exceed above $10 \mathrm{~mA} \mathrm{~cm}^{-2}$, indicating that oxides materials with lower $E_{g}$ and reasonable photovoltage should be investigated.

This review covers the fundamental aspects of protection strategies for tandem PEC water splitting devices, focusing on inorganic thin film materials. First, we review strategies for protecting photoelectrodes, particularly for devices with buried-junctions, and the photo-excited carriers transport mechanisms across photoelectrode/electrolyte interfaces through the protection layers upon PEC water splitting reaction (i.e., 

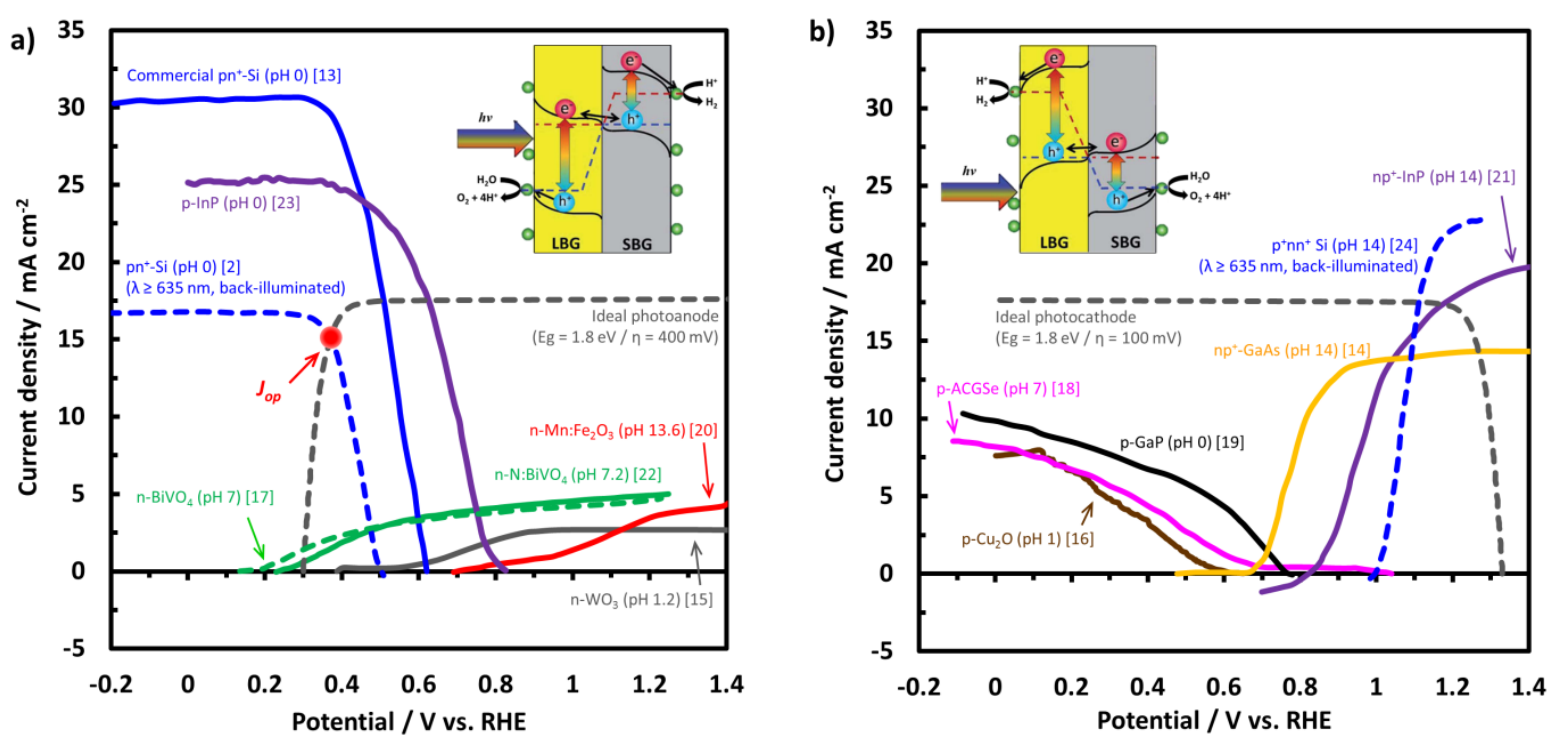

Figure 1. Overlaid current density-potential $(J-V)$ behaviors for state-of-the-art half cells: Combination of small $E_{g}$ (SBG in inset) photocathodes with large $E_{g}$ (LBG in inset) photoanodes (a), and for the case of LBG photocathodes with SBG photoanodes (b). Schema tic drawings for tandem water splitting devices for each case a re illustrated as inset. The dra wings were reproduced with permission from Ref. [10], Copyright 2014 The Royal Society of Chemistry. Modelled J-V curve for photoanode and photocathode (dashed dark grey) a re projected to es timate theoretical maximum $J_{O P}$ of the overall water splitting system. Note that modelled J-V curve for the ideal photoelectrode was drawn using web-based simulation program. ${ }^{25}$ Details of overlayers a nd ca talys ts ca $n$ be found in Ref. [2,13-14].

HER and OER) are described. Secondly, we review various approaches (from the literature) for protecting photoelectrodes and how they impact stability and PEC performance. Finally, key aspects which should be addressed for practical tandem PEC water splitting system are given, along with technical remarks.

\section{Background of protection strategies}

\subsection{Origin of semiconductor instability}

Whether the semiconductor is stable under PEC condition depends on the alignment of the material's selfreduction potential $\left(\Phi_{\text {red }}\right)$ relative to $E\left(\mathrm{H}_{2} / \mathrm{H}_{2} \mathrm{O}\right)$ for the photocathode, and the material's self-oxidation potential $\left(\Phi_{\mathrm{ox}}\right)$ relative to $\mathrm{E}\left(\mathrm{O}_{2} / \mathrm{H}_{2} \mathrm{O}\right)$ for the photoanode, as described in early research by Allen Bard and others. $^{28-30}$ A material is thermodynamically unstable when the $\Phi_{\text {red }}$ and $\Phi_{\text {ox }}$ are placed below or above of $E\left(\mathrm{H}_{2} / \mathrm{H}_{2} \mathrm{O}\right)$ and $\mathrm{E}\left(\mathrm{O}_{2} / \mathrm{H}_{2} \mathrm{O}\right)$, respectively (Fig. 2a, b). Alternatively, when $\Phi_{\text {red }}$ is placed between the conduction band $(\mathrm{CB})$ and $\mathrm{E}\left(\mathrm{H}_{2} / \mathrm{H}_{2} \mathrm{O}\right)$ under $\mathrm{HER}$, the material stability depends on the relative split between the electron consumption rates for material reduction and for HER $\left(k_{H E R}\right)$, which is also called the branching ratio. Similarly, the oxidation reaction competes with consumption rates of photo-generated carriers for water oxidation ( $\left.k_{O E R}\right)$. Most photo electrodes with relatively high photocurrents, such as $\mathrm{Si}$, III-V and chalcopyrite semiconductors etc., are prone to be corroded quickly when in contact with an electrolyte of high ionic strength and, in general, these materials have a very narrow window of stability based on Pourbaix diagrams. ${ }^{29,31,32}$ The photocorrosion 
of the material can be reduced by the use of relevant catalysts which improves charge transfer kinetics (i.e., $k_{\text {HER }}$ or $\left.k_{O E R}\right)$ at the solid/liquid interface, and consequently reduce the surface oxidation. ${ }^{31-33}$ However, this strategy cannot prevent photo electrodes from degradation during night time, where the materials do not have the benefits of photovoltage to provide a stabilizing anodic or cathodic bias. ${ }^{34}$ Kinetic enhancement via morphology modifications can also be an approach for improving the stability of photoelectrodes. For instance, non-planar geometries, such as a rod or pillar array can reduce the distance that minority carriers must travel, and thus the charge transfer kinetics can be significantly improved as shown in previous studies. ${ }^{3,19}$ However, this approach also has the fundamental issue that it does not resolve the problem of degradation in the dark. In the case of $\mathrm{Si}$ - one of the most frequently used photoelectrodes, a Si surface exposed to an acidic electrolyte deactivates by forming oxide or silicic acid, i.e. $\mathrm{SiO}_{2}$ and $\mathrm{H}_{2} \mathrm{SiO}_{3}$ etc., whereas it decomposes into $\mathrm{H}_{2} \mathrm{SiO}_{4}{ }^{2-}$ under strong al kaline condition. ${ }^{33} \mathrm{III-V}$ semiconductors (GaAs, GalnP 2 and others) - photo-absorber materials for the most efficient solar-to-hydrogen conversion efficiencies (STH\%) reported so far (>14\%), ${ }^{26}$ are also prone to chemical decomposition in strong acid where they form $\mathrm{Ga}^{3+}$ species, but this process takes place much more slowly. ${ }^{35}$ Using metal-oxides with high intrinsic chemical stability is also a widely used strategy, however, as described earlier, relatively low PEC performance of those metal-oxides restrict their application in practical water splitting system.

We now turn to the use of high performance non-oxide materials with, e.g. Si. Si has a suitable $E_{g}(1.12 \mathrm{eV})$ for the bottom cell of a tandem water splitting device, and is technologically mature despite the fact it has an indirect band gap and thus at least a $50-\mu \mathrm{m}$-thick absorber is needed in order to achieve substantial optical absorption. ${ }^{2}$ Since Bockris et al. demonstrated a meaningful stability report using a crystalline n-Si photoanode protected by a $\mathrm{Pt}$ thin film under strongly acidic $(\mathrm{pH} \mathrm{0)}$ conditions for water oxidation (i.e., OER) in 1984, several protected Si devices with metallic protective catalyst films, including $\mathrm{Ni}$ (for OER) ${ }^{37}$ and Ti (for HER) ${ }^{38}$ have been demonstrated. However, losses due to parasitic light absorption by metallic layers causes a problem when this strategy is applied for the front-cell in a tandem device structure. Alternatively, metal-oxide semiconductors have been successfully used as protection layers for PEC electrodes owing to relatively high intrinsic chemical stability and minimal parasitic light absorption.

In light of the aforementioned approaches, using a protection layer with a high chemical stability for efficient photoactive semiconductors may provide an appropriate strategy to secure stable water splitting reaction of 
Chem. Soc. Rev. 46, 1933-1954 (2017)

DOI: $10.1039 / \mathrm{c} 6 \mathrm{cs} 00918 \mathrm{~b}$
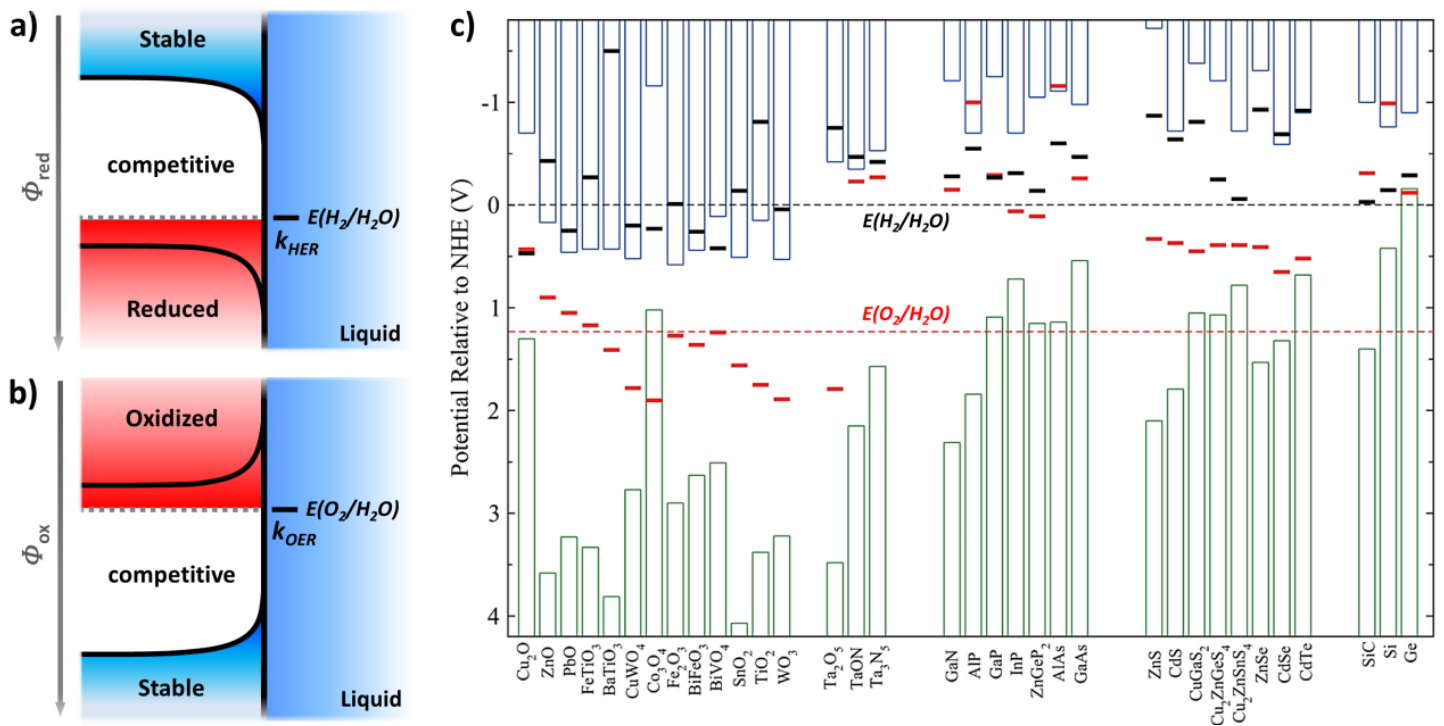

Figure 2. Stability change of the photocathode (a) as its reduction potential $\Phi_{\text {red }}$ shifts down from above the CB of p-type semiconductor to below $E\left(\mathrm{H}_{2} / \mathrm{H}_{2} \mathrm{O}\right)$. Similarly for the photoanode case (b), stability of $n$-type material changes as its oxidation potential $\Phi$ ox increases. Note that the illustration is not to scale. (c) Calculate d reduction potential $\Phi_{\text {red }}$ (black bars) and oxidation potential $\Phi$ ox (red bars) relative to the NHE and vacuum level for a series of semi conductors in solution at $\mathrm{pH}=0$, the ambient temperature $298.15 \mathrm{~K}$, and pressure 1 bar. Figure (c) is reprinted with permission from [29]. Copyright (2012) Ame rican Chemical Society.

PEC electrodes. When the protection layer material has a $\Phi_{\text {red }}$ which is more negative than the CB of the photocathode, the system is thermodynamically stable under HER condition. Similarly, protective material with more positive $\Phi_{\text {ox }}$ than VB of the photoanode can be applied for the OER case. For instance, $\mathrm{TiO}_{2}$ has very negative $\Phi_{\text {red }}$ (relative to RHE) compared to the HER potential ${ }^{29}$ indicating that $\mathrm{TiO}_{2}$ can be an effective protection material for photocathodes, as shown in Fig. $2 c$.

\subsection{Protection strategies and charge transport mechanism}

Since Kohl et al., demonstrated the first reliable HER and OER in $0.5 \mathrm{M} \mathrm{Na}_{2} \mathrm{SO}_{4}(\mathrm{pH} \sim 7)$ using $\mathrm{TiO}_{2}$ protected photoelectrodes in $1977,{ }^{39}$ stable kinetics for various photoelectrodes with metal-oxide protection layer have been identified. Paracchino et al. coated a $\mathrm{p}-\mathrm{Cu}_{2} \mathrm{O} / \mathrm{n}-\mathrm{Al}: \mathrm{ZnO}$ photocathode with a thin $\mathrm{TiO}_{2}(\sim 10 \mathrm{~nm})$ film which shows quite stable PEC activity at relatively lower $\mathrm{pH}(\sim 5) .{ }^{40}$ Starting from this work, Lee et al. demonstrated stable HER using $\mathrm{TiO}_{2}$ protected $\mathrm{p}-\mathrm{InP}$ at $\mathrm{pH} 0 .{ }^{41}$ Chorkendorff and co-workers have also shown stable HER operation using a buried junction crystalline $\mathrm{Si}(\mathrm{c}-\mathrm{Si})$ for both in strongly acidic $\left(1 \mathrm{M} \mathrm{HClO}_{4}\right)^{42,43}$ and strongly alkaline electrolytes $(1 \mathrm{M} \mathrm{KOH}){ }^{34}$ For the photoanode case, Mclntyre and co-workers have demonstrated stable OER both in strong acid $(\mathrm{pH} 0)$ and al kaline $(\mathrm{pH} 14)$ using $\mathrm{TiO}_{2} / \mathrm{Ir}$ protected c-Si with a metal-insulatorsemiconductor charge separation junction which showed a photovoltage $\left(V_{p h}\right)$ of $550 \mathrm{mV} .^{44}$ Lewis and coworkers have shown outstanding stability of 2200 hours (> 90 days) using $\mathrm{TiO}_{2} / \mathrm{Ni}$ protected buried $\mathrm{np}^{+}-$ junction $\mathrm{c}-S \mathrm{i}^{45}$ and $\mathrm{GaAs}^{14}$ under OER condition in $1 \mathrm{M} \mathrm{KOH} \mathrm{(pH} \mathrm{14).} \mathrm{Studies} \mathrm{have} \mathrm{shown} \mathrm{that} \mathrm{multiple}$ 
Chem. Soc. Rev. 46, 1933-1954 (2017)

DOI: $10.1039 / \mathrm{c} 6 \mathrm{cs} 00918 \mathrm{~b}$

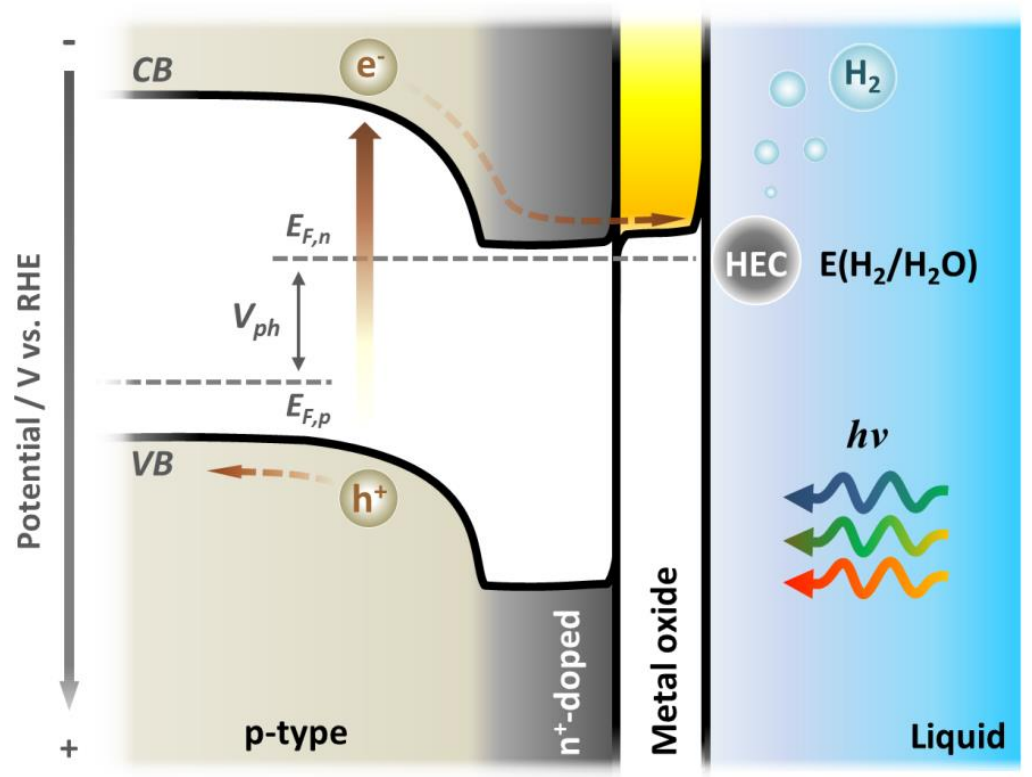

Figure 3. A schematicillus tration of the band diagram of a photocathode with a buried $\mathrm{pn}^{+}$-junction protected bya $\mathrm{n}$-type metallic oxide passivation layer. HEC stands for the hydrogen evolution catalyst, and $E_{F, n}$ and $E_{F, p}$ stand for the quasi-Fermi level for the electron a nd hole, respectively, the difference of which gives the photovoltage $\left(V_{p h}\right)$ under illumination.

properties of the protection layer should be optimized for efficient charge transport under PEC conditions, including, but not limited to conductivity type, and band bending across the thickness. In general, metal oxide layers with $\mathrm{n}$-type conductivity have been investigated as cathodic protection layers for HER. ${ }^{16,40,43,46}$ It has been widely accepted that electrons separated by a buried junction migrate to solid/liquid interface through the $C B$ of $n$-type protection materials,,$^{2,13,40,43,46,47}$ as shown in Fig. 3 .

Inversely, metal oxide layers with $p$-type conductivity coupled with photoanodes can transport holes via VB of the protection layer to the solid/liquid interface for OER (see Fig. 4a). In case of very thin (less than $2 \mathrm{~nm}$ thick) oxide insulators, such as $\mathrm{SiO}_{2}$ and $\mathrm{Al}_{2} \mathrm{O}_{3}$, direct tunnelling of charge carriers across the protection layers have also been reported, ${ }^{43,48}$ as illustrated in Fig. 4b. Interestingly, Hu et al. ${ }^{14}$ reported that a thick amorphous $\mathrm{TiO}_{2}$ protection layer is applicable for the protection of photoanodes for OER due to hole transport through the bulk and a surface barrier of a "leaky" $\mathrm{TiO}_{2}$ owing to defects in the bulk of the protection layer, which is also known as a state-mediated transport (see also Fig. 4c), as introduced by Campet et al. in $1989 .{ }^{49}$ In the case of highly-doped n-type protection layer for photoanodes, electrons created by the OER reaction are injected into the $\mathrm{CB}$ of the protection layer and transported inwards toward the underlying photoabsorber. The electrons in the protection layer's CB then recombine with holes at the interface between the photoanode and the protection layer. The holes to recombine with electrons from the $C B$ of the protection layer are the photogenerated holes transported through the VB of photoabsorber (which is aligned with the CB of the 
Chem. Soc. Rev. 46, 1933-1954 (2017)

DOI: $10.1039 / \mathrm{c} 6 \mathrm{cs} 00918 \mathrm{~b}$
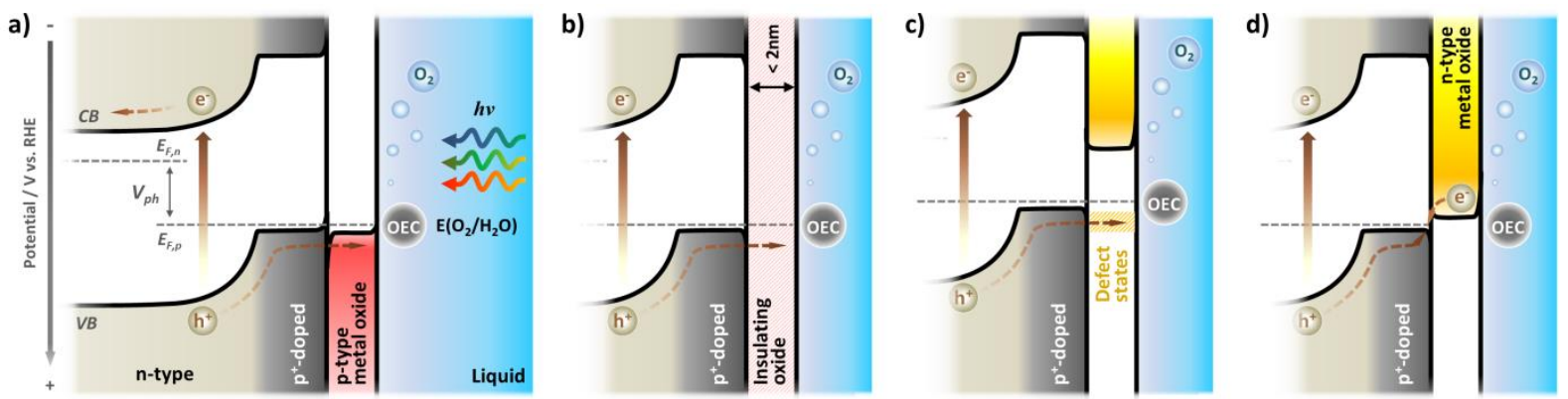

Figure 4. Illustration of band diagrams for protected buried $n p^{+}$-junction photoanode with various charge transport mechanisms: a) hole-transport via VB of $p$-type protection layer; b) hole-tunneling through the thin insulating oxide; $c_{\text {; }}^{\prime}$ hole-injection via state-mediate transport; d) electron consumption by recombination at the interface between the photoanode and $\mathrm{n}$-type protection layer. Note that OEC s tands for oxygen evolution catalyst.

protection layer (see Fig. 4d)), as shown by Mei et al. using c-Si and $\mathrm{TiO}_{2} \cdot{ }^{50}$ In other words, this form of photoanode protection layer transports electrons in - instead transporting holes out. Besides the above mentioned $\mathrm{TiO}_{2}$ and other insulating oxides, various types of transition metal oxides, including $\mathrm{NiO}_{x}$, and $\mathrm{CoO}_{x}$, have shown to be applicable depending on the operating condition and chemical reaction type. Further details for each case will be reviewed in the following sections.

\section{Protection of photocathodes}

Early experiments in solar-assisted hydrogen evolution emphasized the use of low band-gap solar cell materials, such as $\mathrm{p}$-type $\mathrm{Si}^{51}$ and $\operatorname{InP}{ }^{52,53}$ by having HER catalyst (e.g. $\mathrm{Pt}^{51}$ and $\mathrm{Rh}^{53}$ ) at the surface of those semiconductors. In these early studies of PEC electrodes for HER reaction, not much effort was devoted to protection of semiconductor surface from degradation, beca use those photocathodes materials were covered by oxide phase, such as $\mathrm{SiO}_{2}$, which is formed during cathodic reaction under oxygen contamination, or they have very slow decomposition reaction kinetics in such conditions. However, this kind of self-oxidation cannot be categorized as a protection layer in regard to the negative effect, i.e., that oxidized surface hinders efficient charge transport leading to deactivation of the photoelectrode. 
Chem. Soc. Rev. 46, 1933-1954 (2017)

DOI: $10.1039 / \mathrm{c} 6 \mathrm{cs} 00918 \mathrm{~b}$

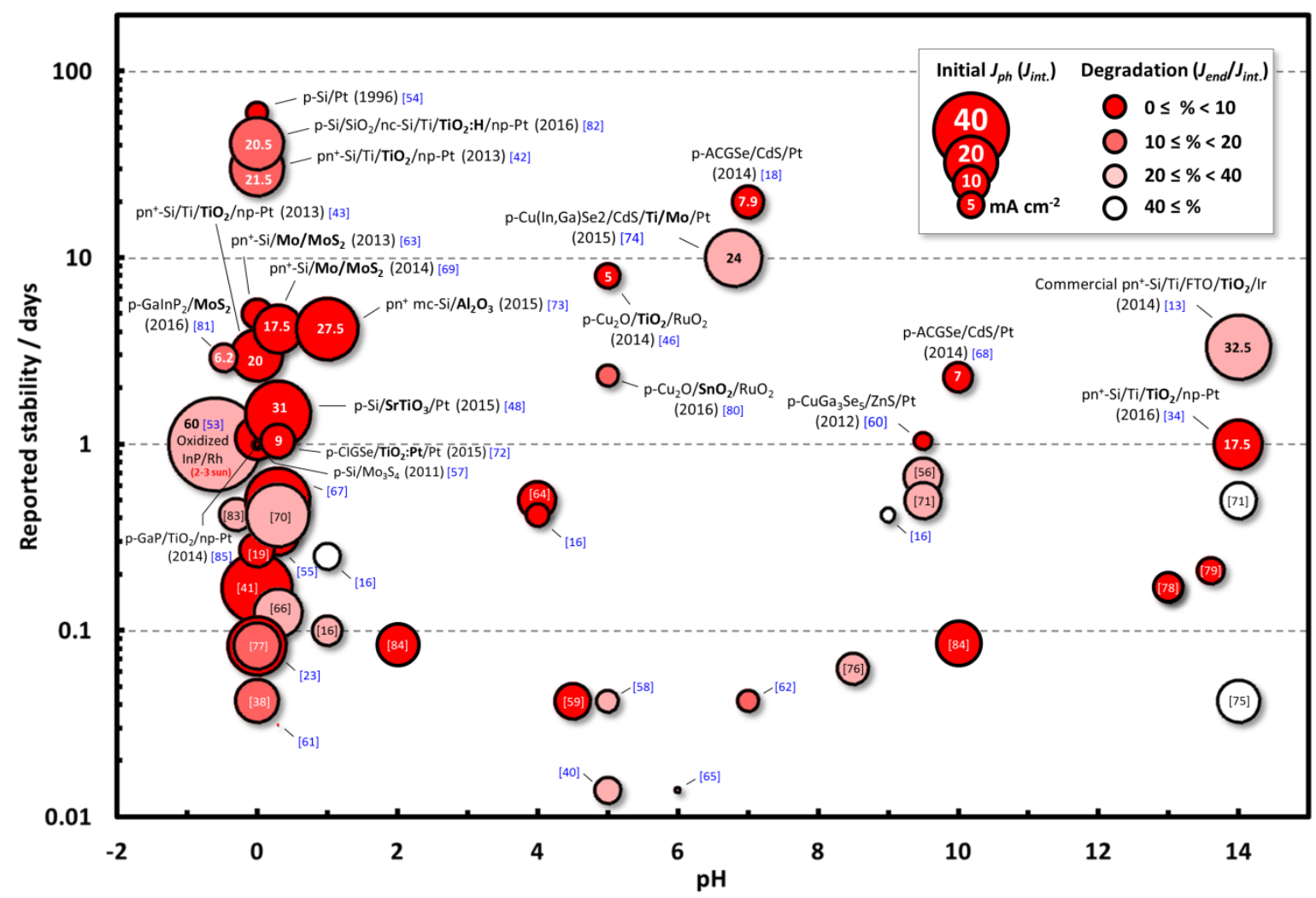

Figure 5. Chart visualizing data on reported stabilities of photocath odes for HER, versus tes ted pH condition, with resulting photocurrent and degradation rate indicated. Device structures for photocathode with reported stabilitylonger than a day a re noted. $J_{\text {int. }}$ is the initial photocurrent at the $s$ tart of the stability test. Degradation rates a re calcula ted using the ratio of the measured photocurrent at the end of the stability test $\left(U_{\text {end }}\right)$ to $J_{\text {int. }}$. Detailed information on device structures and working conditions also can also be found in Table S1 in ESIt.

Figure 5 summarizes the reported stability for many HER photocathode materials plotted against the pH level during the test. Note that for reported stabilities of overall water splitting from tandem or multi-junction devices the origin of degradation (HER or OER part) cannot be specified. Experimental details and device structures of the collected data from refs. ${ }^{13,16,18,19,23,34,38,40-43,46,48,53-85}$ in Figure 5 can be found in Table S1 in ESIt. As shown in Figure 5, most stability studies on HER are done in acid condition, particularly near $\mathrm{pH} 0$, because many photoabsorber semiconductors are relatively stable under such conditions as stated previously. Notwithstanding of this nature of photocathode semiconductors, the importance of having long-term stable HER kinetics has to be emphasized. Since Maier et al. demonstrated 60 days long-term HER at pH 0 using ptype c-Si coupled with a photo-electrochemically deposited Pt layer, ${ }^{54}$ various type of metallic layers have been applied as a protective HER catalysts. However, these metallic layers often limit efficient photocurrent output, even though they can isolate the photo-absorber effectively from the corrosive electrolyte, due to parasitic light absorption/reflection of the metallic elements. Nevertheless, they can be used for bottom cell applications, as described previously. Photocurrent output of most of the metallic HEC (hydrogen evolution 
catalyst) coated c-Si based photoelectrodes $\left(\sim 10 \mathrm{~mA} \mathrm{~cm}^{-2}\right)^{53,59}$ are far from both the theoretical limit as well as experimentally obtained values from commercial c-Si PV cells, which exceeds $40 \mathrm{~mA} \mathrm{~cm}^{-2}$ under full AM1.5G illumination. 2,86

Transparent metal oxides are widely used as protection layers of photocathode materials. As described in the previous section, many metallic oxides are stable under water reducing conditions. ${ }^{33}$ In addition, the relatively high intrinsic chemical stability of these metal-oxide semiconductors under dark condition ${ }^{34}$ paves the way for the practical application in PEC water splitting devices. Furthermore, some metal oxides, such as $\mathrm{TiO}_{2}$, which has band-gap of around $3.2 \mathrm{eV}^{50,87}$ provide excellent optical transmittance in visible light region. Alternatively, thin metallic oxide insulators, such as $\mathrm{SiO}$ and $\mathrm{Al}_{2} \mathrm{O}_{3}$, can be used as a protection layer. Depending on the semiconductor type and reducing condition, these insulating layers can be formed naturally when the photocathode material has direct contact with the electrolyte. In 1982, Heller et al. reported the formation of a thin 'native' oxide on $\mathrm{p}-\mathrm{InP}$ surface by a 16 hours exposure to humid air, ${ }^{53}$ which allowed for a quite stable PEC hydrogen production for a 24 hours. In an attempt to seek more uniform metal oxide formation approaches, several groups have reported use of an ultra-thin $\mathrm{Al}_{2} \mathrm{O}_{3}$ layer on $\mathrm{p}-\mathrm{Si},{ }^{67,88}$ deposited using $\mathrm{ALD}$ (atomic layer deposition) which provides a compact layer with sub-nanometer (usually sub-angstrom) precision. ${ }^{89}$ In various device designs, $\mathrm{TiO}_{2}$ protected photocathodes are widely used over a wide $\mathrm{pH}$ range from acid to alkaline. Narrowing the $\mathrm{pH}$ range to near 0 , Mo-based sulphides semiconductors (e.g., $\mathrm{MoS}_{2}$ ) are also widely used as a protective HEC layer. The following sections discuss recent progress in stabilization of PEC hydrogen production, and both the limitations and prospects towards practical water splitting devices.

\subsection{Metallic layers}

Despite the parasitic light absorption issue, metals have been employed as protection layers for photocathodes without hindering charge transfer owing to their outstanding intrinsic conductive properties. Maier et al. demonstrated 60 days stable PEC hydrogen production using Pt coated p-type c-Si with $0.3 \mathrm{~V}$ of onset potential $\left(V_{o n}\right)$ in $1 \mathrm{M} \mathrm{HCl}(\mathrm{pH} 0) .{ }^{54}$ Generally, noble metals are widely used as protection layers, but some non-noble metallic elements may also be used depending on working condition and device configuration. Moreover, the metals with a lower work-function than the photoabsorber, e.g., $\mathrm{Ti}$ with $\mathrm{p}-\mathrm{Si},{ }^{90}$ leads to a formation of a Schottky junction between the metal and semiconductor and introduces a built-in electric field, which promotes charge separation as shown in Fig. 6 . In a recent report by Feng et al., a $5 \mathrm{~nm}$ Ti layer coupled 
Chem. Soc. Rev. 46, 1933-1954 (2017)

DOI: $10.1039 / \mathrm{c} 6 \mathrm{cs} 00918 \mathrm{~b}$

a)

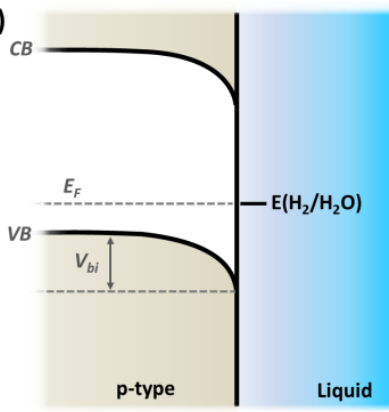

b)

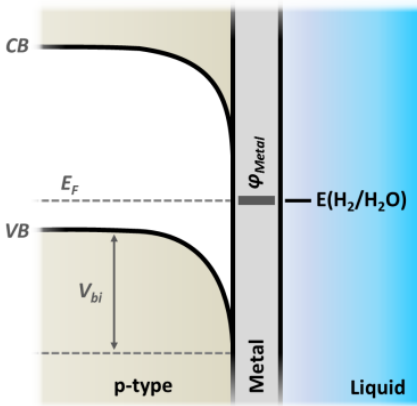

c)

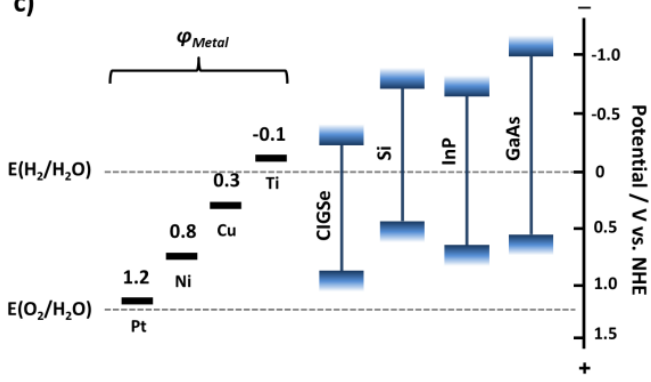

Figure 6. Proposed band diagra ms for pris tine p-type semiconductor (a) and metal-protected semi conductor with Schottky. junction (b) in equilibrium with the $\mathrm{H}_{2} / \mathrm{H}_{2} \mathrm{O}$ redox couple in contact with electrolyte. $V_{b i}$ stands for the built-in potential. Band positions of widely used non-oxide photoabsorbers with approximate work function $\left(\varphi_{\text {metal }}\right)$ of selected metals are also shown in (c). The potential values in (c) a re reported in the literature ${ }^{29,90}$ and relative to NHE (normal hydrogen electrode).

with a $2 \mathrm{~nm} \mathrm{Ni}$ catalytic layers showed a $V_{\text {on }}$ around $0.3 \mathrm{~V}$ vs. RHE with quite stable HER under illumination for 12 hours in both in $1 \mathrm{M} \mathrm{KBi}(\mathrm{pH} 9.5)$ and $1 \mathrm{M} \mathrm{KOH}(\mathrm{pH} \mathrm{14}) .{ }^{91}$ A demerit of this approach is that there is generally a significant carrier recombination at the metal/semiconductor Schottky junction interface, which results in very limited photovoltages. Seger et al. ${ }^{38}$ used a thin Ti protection layer for $\mathrm{HER}$ in $1 \mathrm{M} \mathrm{HClO}_{4}(\mathrm{pH} 0)$ between a $\mathrm{pn}^{+}$-Si photoelectrode and $\mathrm{MoS}_{\mathrm{x}}$ layer, which had $V_{\text {on }}$ of $0.33 \mathrm{~V}$ vs. RHE $(0.47 \mathrm{~V}$ with $\mathrm{Pt})$ with a relatively high fill factor owing to the buried $\mathrm{pn}^{+}$-junction. Unlike the previously mentioned semiconductor/metal direct contact which forms a Schottky junction, the contact of a metallic layer with a highly-doped semiconductor surface shows an Ohmic behaviour.

Despite the simplicity of the fabrication process of the metal protection layer, its application has been limited due to parasitic light absorption/reflection by these metallic layers. However, there should be no issues with light absorption/reflection for the case of the bottom cell in a tandem device configuration, since protection layers only need to be transparent when the illuminated side and the reaction side are coincident. ${ }^{10}$ As shown in recent works by Bae et al. ${ }^{2}$ and Urbain et al., ${ }^{78} \mathrm{HEC}$ acts under a pure dark electrocatalytic condition when the light is incident from the opposite side, thus indicating that bottom cell photoelectrodes in tandem water splitting device can be protected using a metallic layer regardless of its thickness. Recently, Crespo-Quesada et al. $^{76}$ demonstrated quite stable photocurrent output $\left(\sim 7.7 \mathrm{~mA} \mathrm{~cm}^{-2}\right)$ under back-side illumination for 1.5 hours in $0.1 \mathrm{M}$ borate electrolyte $(\mathrm{pH} \quad 8.5)$ using a organometallic halide perovskite-based device (FTO/PEDOT:PSS/ $\mathrm{CH}_{3} \mathrm{NH}_{3} \mathrm{Pbl}_{3} / \mathrm{PCBM}$ ) coupled with thick Ag and Field's Metal (FM; InBiSn alloy), indicating that even water-sensitive semiconductors, such as lead halide type perovskites, can be used for PEC purpose with an appropriate protection strategy. 
Chem. Soc. Rev. 46, 1933-1954 (2017)

DOI: $10.1039 / \mathrm{c} 6 \mathrm{cs} 00918 \mathrm{~b}$

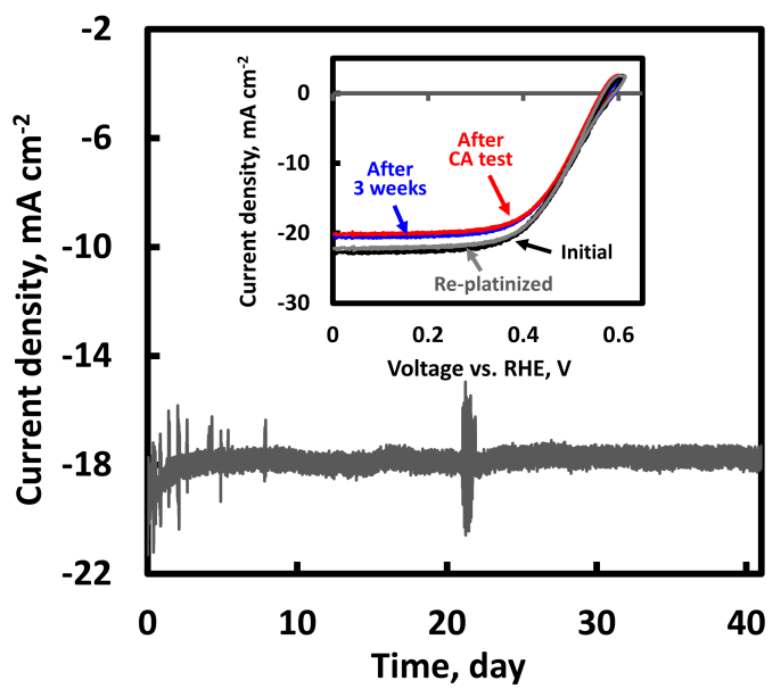

Figure 7. Long-term stability (chromoamperometry - CA) test of forming-gas $\left(5 \% \mathrm{H}_{2} / \mathrm{Ar}\right.$ ) trea ted carrier-selective c-Si photocathode (c-Si/SiO $/ \mathrm{nc}-\mathrm{Si}$ at both front \& back contacts) with 100-nm-thick sputtered $\mathrm{TiO}_{2}$ protection layer. Photocurrent was measured at $0.4 \mathrm{~V}$ vs. RHE in $1 \mathrm{M} \mathrm{HdO}_{4}(\mathrm{pH} 0)$. Initial CV prior to the CA measurement (black), $\mathrm{CV}$ after 3 weeks (blue), after 41 days (red), and CV from a re-platinized sample after the long-term CA test (grey) are shown in the ins et. The figure is reprinted from ref. [82] with permission from Elsevier, Copyright 2016.

\subsection{Metallic oxides}

Many of the metal oxides are excellent protection layers for HER, however, as described in the previous section, $\mathrm{TiO}_{2}$ is the most widely used protective metallic oxide material over the full $\mathrm{pH}$ range. At the same time, owing to its excellent optical transmittance $\left(E_{g} \geq 3.0 \mathrm{eV}\right)^{28,50}$ and good electron conductivity, most low band-gap photocathodes coupled with $\mathrm{TiO}_{2}$ show relatively high photocurrent above $20 \mathrm{~mA} \mathrm{~cm}$-2 under illumination. ${ }^{23,41,43,82}$ Compared to other types of protection layers, $\mathrm{TiO}_{2}$ protected photocathodes show relatively long-term stable operation with high photocurrent output. It has been shown that a $\mathrm{TiO}_{2}$ protected c-Si (100) with a buried $\mathrm{pn}^{+}$-junction delivered a current density over $21 \mathrm{~mA} \mathrm{~cm}{ }^{-2}$ at $0.3 \mathrm{~V}$ vs. RHE with relatively low photocurrent loss $(\sim 14 \%)$ for 30 days under red-light $\left(38.6 \mathrm{~mW} \mathrm{~cm}{ }^{-2} ; \lambda \geq 635 \mathrm{~nm}\right.$ ) filtered, simulated sunlight. ${ }^{42}$ More recently, a $\mathrm{TiO}_{2}$ protected MOS-based $\mathrm{Si}$ photocathode (c-Si/SiOx/nc-Si) also delivered 41 days stable HER operation under the same PEC condition (Fig. 7), ${ }^{82}$ indicating that not only c-Si, but also chemically deposited thin-film Si can be successfully protected by $\mathrm{TiO}_{2}$ under water reduction conditions in an acidic environment. The interfacing between the photoabsorber and protection layer is a critical factor for efficient charge transfer for high catalytic activity. The direct deposition of metal oxides may lead to surface oxidization of the photocathode (e.g. $\mathrm{SiO}_{\mathrm{x}}$ ) that builds an energy barrier which hinders photogenerated electron transport. A metallic and/or conducting interlayer applied between the metal oxide protection layer and photoanode can prevent the formation of an insulating layer during the subsequent deposition process. It has been shown that a thin Ti $(5 \sim 10 \mathrm{~nm})$ metallic interlayer can protect the Si surface 
a)

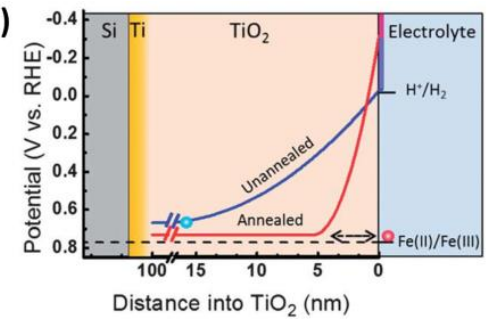

b)

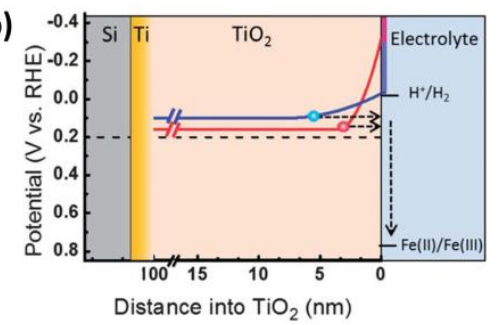

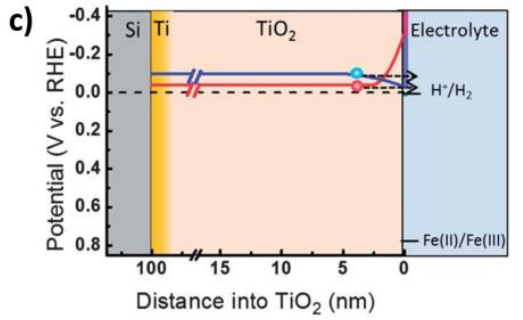

Figure 8. These band diagrams show the location of the $\mathrm{TiO}_{2}$ conduction band of both the unannealed (blue lines) and va cuum a nnealed (red lines) samples as a function of depth into $\mathrm{TiO}_{2}$ at the following ele ctrochemical potentials: $(\mathrm{A})+0.7 \mathrm{I}$ $\mathrm{V},(\mathrm{B})+0.2 \mathrm{~V}$ and (C) $0.0 \mathrm{~V}$ vs. RHE. Note that the conduction band (CB) pinning at the $\mathrm{TiO}_{2} /$ electrolyte interface. Electrons can tunnel through the $\mathrm{TiO}_{2}$ only at the low potential range due to relatively wide depletion width, which hinders the efficient carrier transport. This figure was reproduced with permission from Ref. [47], Copyright 2013 The Royal Society of Chemistry.

against deactivation by sacrificial-oxidation of $\mathrm{Ti}$ interlayer at high temperature $\mathrm{TiO}_{2}$ deposition process. ${ }^{2,13,34,43,50}$

The doping level of the metal oxide layer is also a key parameter for efficient charge transport through oxide protection layer. High doping levels generally result in thin depletion layers, where tunnelling of the electrons at the CB of the oxide protection layer through the Schottky-barrier and at the oxide/liquid interface is possible. When the doping level is extremely high, this interface shows Ohmic-like behaviour as described earlier in chapter 2. In the case of $\mathrm{TiO}_{2}$, the doping level can easily be adjusted in an annealing process in vacuum which results in oxygen vacancies, and consequently increased dopant density. Seger et al. ${ }^{47}$ revealed experimentally the importance of having a high doping level in the metal oxide protection layer by using photocathodes with two different doping levels. As shown in Figure 8, low-doped $\mathrm{TiO}_{2}$ (unannealed) has a relatively long depletion width that electrons cannot tunnel through, while highly-doped $\mathrm{TiO}_{2}$ (vacuum annealed) exhibits quite thin depletion width and with the donor density an order of magnitude higher than that of the unannealed film so that electrons can be injected to the electrolyte at lower potential than required for low-doped $\mathrm{TiO}_{2} \mathrm{case}_{\text {. }}$ Similarly, Liang et al. ${ }^{79}$ also demonstrated in their recent work that the $\mathrm{H}$-doping via deposition of $\mathrm{TiO}_{2}$ under $\mathrm{H}_{2} / \mathrm{Ar}$ gas mixture flow can increase carrier density leading to enhancement of electron transport in $\mathrm{TiO}_{2}$ films and a shorter depletion layer barrier.

In general, protective metal oxides, including $\mathrm{TiO}_{2}$, are poor $\mathrm{HER}$ catalyst, and thus coupling with a co-catalyst, such as Pt and Ru, is preferred for efficient HER kinetics. Taking into account parasitic light absorption of the metallic layer, a metal oxide protected photocathode coupled with thin covering co-catalyst film loses the merit of using metal-oxide protection layer. For this reason, catalysts in form of nanoparticles or small islands are preferred. Uniformly distributed $\mathrm{Pt}$ nanoparticles $(\sim 5 \mathrm{~nm})$ formed on the $\mathrm{TiO}_{2}$ surface by the 
a.

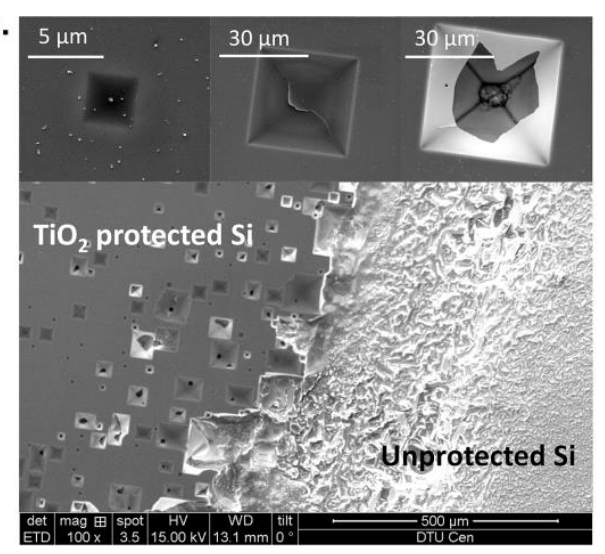

b.

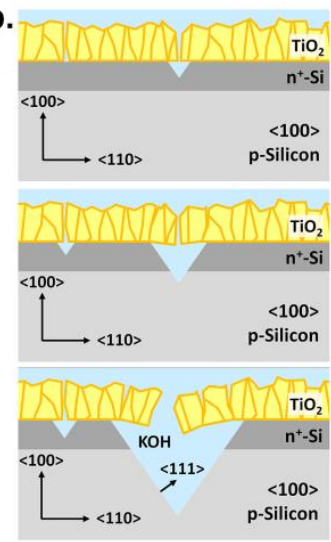

Figure 9. SEM images of a (100) oriented $\mathrm{C}$-Si subs trate with and without sputter deposited $\mathrm{TiO}_{2}$ at $400{ }^{\circ} \mathrm{C}$ afterimmersion in an $1 \mathrm{M} \mathrm{KOH}$ electrolyte $(\mathrm{pH} \mathrm{14)}$ for 3 days in the dark (a), and illustrations of the etch profiles of a (100) oriented Si through the pin-holes of $\mathrm{TiO}_{2}$ protection layer during e tching process in $\mathrm{KOH}$ solution. The figures we re a dapted from Ref. [34], copyright (2016) with permission from Elsevier.

(photo)electro-deposition method ${ }^{2,34,43,82}$ can support efficient catalytic HER and allow sufficient light transmission through the protective layer at the same time. However, this approach cannot prevent the simultaneous loss of Pt nanoparticles by the potential loss of $\mathrm{TiO}_{2}$ during long-term experiments. To solve this problem, use of a mixed phase of $\mathrm{TiO}_{2}$ and $\mathrm{Pt}(5 \%)$ has been demonstrated to protect a chalcopyrite photocathode $\left(\mathrm{p}-\mathrm{Cu}(\mathrm{In}, \mathrm{Ga}) \mathrm{Se}_{2}\right)$ under acidic conditions $\left(0.5 \mathrm{M} \mathrm{H}_{2} \mathrm{SO}_{4}, \mathrm{pH} \sim 0.3\right)$ in recent work by Azarpira et al., ${ }^{92}$ where Pt particles are well distributed in bulk $\mathrm{TiO}_{2}$ layer so that the photoelectrode could operate stable HER without significant degradation regardless of $\mathrm{TiO}_{2}$ loss. It has also been demonstrated that earthabundant catalysts, such as $\operatorname{MoS}_{x}$, also can be applied as an additive for photocathode protection layer in acidic conditions. Bourgeteau et al. ${ }^{61}$ spin-coated mixed $\mathrm{TiO}_{2}$ and $\mathrm{MoS}_{3}$ nanoparticles and formed a thick $\mathrm{TiO}_{2}: \mathrm{MoS}_{3}$ protection layer $(90 \mathrm{~nm})$ onto a hetero-junction organic solar cell (ITO/PEDOT:PSS/P3HT:PCBM), which shows $V_{\text {on }}$ above $0.5 \mathrm{~V}$ in low $\mathrm{pH}$ condition $\left(0.5 \mathrm{M} \mathrm{H}_{2} \mathrm{SO}_{4}, \mathrm{pH} 0.3\right)$. Although its photocurrent is quite low ( $0.23 \mathrm{~mA} \mathrm{~cm}{ }^{-2} @ 0 V$ vs. RHE), it is noteworthy that it was a first time demonstration of quite stable HER operation using an organic solar cell in such conditions under continuous illumination (45 min).

The use of an n-type $\mathrm{Nb}_{2} \mathrm{O}_{5}$ protection layer also deserves serious consideration since its protective property in acidic condition has also been shown, ${ }^{85}$ using a planar type $\mathrm{p}-\mathrm{GaP} / \mathrm{n}-\mathrm{Nb}_{2} \mathrm{O}_{5} / \mathrm{np}$-Pt with a quite high $V_{\text {on }}$ of 710 $\mathrm{mV}$ and stable photocurrent for 8 hours in $1 \mathrm{M} \mathrm{HClO}_{4}$. Despite of the subsequent slow degradation after the 8 hours, Nb-based metal oxide may prove to be one of the promising materials for protection of p-type materials, since it has a wide stability window in the Pourbaix diagram from $\mathrm{pH} 0.5$ to $6.5 .^{33}$ Standing et al. ${ }^{19}$ also demonstrated $V_{\text {on }}$ above $0.75 \mathrm{~V}$ with significantly increased photocurrent $\left(\sim 9 \mathrm{~mA} \mathrm{~cm}{ }^{-2} @ 0 V\right.$ vs. RHE) using nanowire (NW) Pt-coupled p-GaP, whose surface was chemically oxidized. Despite of this encouraging PEC 

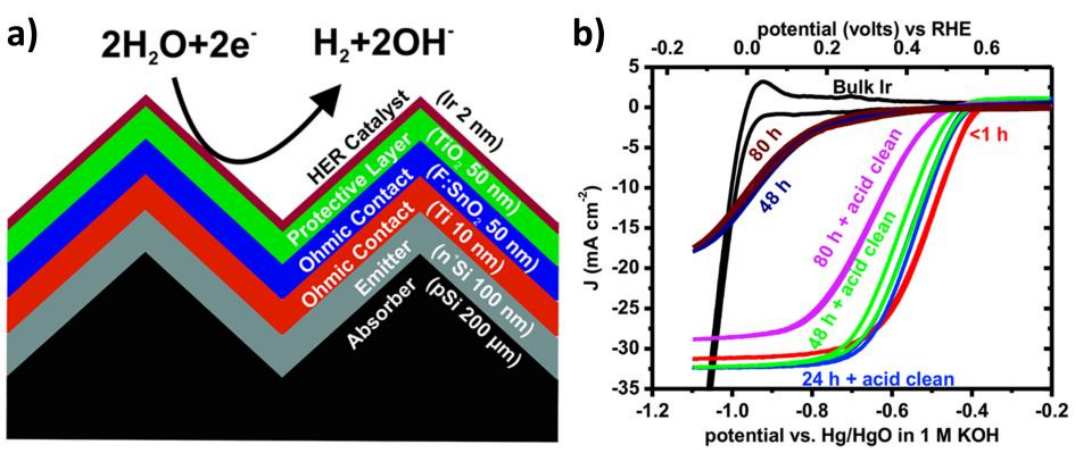

Figure 10. (a) Schematic of protected textured cells with catalyst and Ohmic-contact layers demonstrated in ref. [12] Solution processed $\mathrm{TiO}_{2}$ layer has been applied as a protection layer, and both $\mathrm{Ti}$ and FTO (F-doped tin oxide) are used as Ohmic-contact layers for efficient lateral charge transport. (b) J-V curves from CVs of photocathode after various times and trea tments of stability tes ting at $300 \mathrm{mV}$ vs. RHE (near maximum power point) in $1 \mathrm{M} \mathrm{KOH} \mathrm{(pH} \mathrm{14).} \mathrm{The} \mathrm{photocathode} \mathrm{was}$ then cleaned in acid $(1 \mathrm{M} \mathrm{HClO4})$ via cycling from reducing to oxidizing potentials. Reprinted with permission from Ref. [12]. Copyright (2014) Ame rican Che mical Society.

activity, state-of-the-art PEC GaP's photovoltage lags behind the state-of-the-art GaP PV cell (1.56 V), thus there is still plenty of room for improvement.

Among the various metal oxide protected photocathodes with reported stability at mid-pH range, $\mathrm{SnO}_{2}$ is noteworthy. Azevedo et al. demonstrated a $\mathrm{SnO}_{2}(50 \mathrm{~nm})$ protected $\mathrm{p}-\mathrm{Cu}_{2} \mathrm{O}$ photocathode in their recent work, ${ }^{80}$ where the $\mathrm{RuO}_{2}$ coupled photocathode showed a $V_{\text {on }} \sim 0.34 \mathrm{~V}$ with quite stable cathodic photocurrent for more than 2.3 days at $\mathrm{pH}$ 5. In addition, a $\mathrm{Cu}_{2} \mathrm{O}$ photocathode with $\mathrm{ZnO} / \mathrm{SnO}_{2}$ dual protection layer increased $V_{\text {on }}(\sim 0.55 \mathrm{~V}$ vs. RHE) and stability such that the system operated in the same conditions for 28 hours with only a relatively minimal in PEC activity.

However, unlike in acidic conditions, where the corrosion rate of the photocathode is generally slow due to self-limiting passivation of $\mathrm{Si}$ interface to $\mathrm{SiO}_{2},{ }^{34}$ many photocathode semiconductors dissolve quite easily in alkaline electrolytes. When $\mathrm{Si}$ interacts with alkaline solution it corrodes via dissolution into $\mathrm{SiO}_{4}{ }^{-}$( $\mathrm{rather}$ than $\mathrm{SiO}_{2}$ ). The wide stability window of $\mathrm{TiO}_{2}$ in the Pourbaix diagram implies that $\mathrm{TiO}_{2}$ can be applied in alkaline electrolyte as demonstrated in recent studies..$^{34,79}$ Though irrespective of the 'intrinsic' stability of the $\mathrm{TiO}_{2}$ semiconductor, the lack of a self-limiting passivation entails that the underlying Si will corrode continuously under any pinhole in protection layer, as shown in Figure 9. Kast et al. ${ }^{13}$ demonstrated the best performance cSi based photocathode using a commercial textured $\mathrm{pn}^{+}-\mathrm{Si}$ solar cell device protected by complex multi-layer configuration of $\mathrm{Ti} / \mathrm{FTO} / \mathrm{TiO}_{2} / \mathrm{Ir}(10 / 50 / 50 / 2 \mathrm{~nm})$. Ti and $\mathrm{FTO}$ layers were used as Ohmic-contact layers between a sprayed $\mathrm{TiO}_{2}$ protection layer and a textured c-Si solar cell to provide a lateral electron pathway which can reduce the effect of locally deactivated regions by oxidation. As shown in Fig. 10, the sample showed significant decrease in activity after 2-days-operation, which was recovered after cleaning in acid. This 
indicates that the degradation may be attributed to catalyst poisoning. However, an unrestored CV after the 3 days reveals physical damage on C-Si, which was proven by cross-sectional microscopic analysis. Bae et al. in Ref. $^{34}$ have also proved that p-type c-Si (100) can be protected for 24 hours in highly alkaline conditions (pH 14) using high power impulse magnetron sputtering (HiPIMS) that provides a $\mathrm{TiO}_{2}$ protection layer with relatively high packing density, thus reducing pinhole density and the aforementioned issues accompanying them.

The fabrication method, in this sense, is of great importance. Conformal ALD coatings with outstanding stepcoverage have also been applied for protection of photocathodes in alkaline media. Recently, a relatively thin $(25 \mathrm{~nm}) \mathrm{ALD} \mathrm{TiO}_{2}$ was deposited on a p-i-n a-SiC photocathode and PEC hydrogen production was performed in $1 \mathrm{M} \mathrm{KOH} \mathrm{(pH} \mathrm{14).}{ }^{75}$ Unlike the previously mentioned cases in Refs., ${ }^{13,34}$ ALD $\mathrm{TiO}_{2}$ coated a-SiC shows a stable photocurrent for only 40 minutes, followed by a rapid deactivation, which leaves only $35 \%$ of the initial photocurrent after 1 hour. This was attributed mainly to uncovered pinholes in $\mathrm{TiO}_{2}$ that exposed a-SiC to the highly corrosive electrolyte, which subsequently etched the a-SiC. This may be related closely with the fabrication conditions during protection layer deposition. Pinholes on the protection layer can be reduced or minimized by forming a dense and compactlayer, but contamination, such as dust particles or debris adsorbed on the surface, cannot be removed simply by changing the deposition technique. Considering the fact that the above mentioned experiments were not carried out under the cleanroom conditions, much more stable PEC activities may be obtained if deposition is done in dust-free conditions. Deposition of metal oxide protection layer at larger thickness will certainly reduce pinhole density, however, thicker films will also increase series resistance and could additionally build a tunnelling barrier. The thickness-dependency of metal oxide resistance is noticeable, particularly, in the case of metallic oxides with low doping level. As shown in Fig. 8, a highly-doped metal oxide is required for efficient electron transfer across the $\mathrm{TiO}_{2} /$ electrolyte interface. Alternatively, the thickness of the protection layer should be thin enough to tunnel through $(<2 \mathrm{~nm})$ as described in chapter 2.2 .

Except for the previously mentioned works of Heller et al. from the early 1980 's, ${ }^{52,53}$ the protection property of several insulating metal oxide also have been verified recently. $\mathrm{Al}_{2} \mathrm{O}_{3}$ is a well reported insulator, which can protect photoelectrodes from corrosion in electrolytes, while photo-induced free carriers can tunnel through and then react with protons to produce hydrogen. Choi et al. ${ }^{67}$ demonstrated a nanoporous (Np) $\mathrm{Si}$ photocathode protected by a thin $\mathrm{Al}_{2} \mathrm{O}_{3}(2.3 \mathrm{~nm})$, which performed 12 -hours-long stable cathodic current output in $0.5 \mathrm{M} \mathrm{H}_{2} \mathrm{SO}_{4}(\mathrm{pH} \mathrm{0.3)}$. An interesting feature is that the long-term stability test was performed at a 
fixed negative potential at $-0.3 \mathrm{~V}$ vs. $\mathrm{RHE}$ in $\mathrm{pH} 0.3$, where $\mathrm{Al}_{2} \mathrm{O}_{3}$ is reduced to $\mathrm{Al}^{+}$. The stability of the $\mathrm{Al}_{2} \mathrm{O}_{3}$ protection layer after the long-term stability test is of doubtful, because $\mathrm{Al}$ is prone to be reduced and the $\mathrm{Si}$ surface tends to oxidize (i.e., $\mathrm{SiO}_{\mathrm{X}}$ ) in such conditions as demonstrated by Maier et al. and others. ${ }^{54,57,59} \mathrm{Ji}$ et al. ${ }^{48}$ demonstrated a metal-insulator-semiconductor (MIS) PEC cell, where a thin $\mathrm{SrTiO}_{3}$ (STO) (1.6 nm) layer was used as a protective insulator, and very stable PEC activity (>31 mA cm ${ }^{-2} @ 0 \mathrm{~V}$ vs. $\mathrm{Ag} / \mathrm{AgCl}$ under $\left.1-\mathrm{sun}\right)$ was performed with a Pt co-catalyst for 1.5 days. Interestingly, it has been claimed that electrons can be injected through the conduction-band of C-Si and through the MBE-grown STO on Si due to the small band offset between these two materials (see Fig. 11a inset). However, detailed description or calculation of the low band-offset at the c-Si/STO interface was not provided. Although Pt is an excellent HEC, its large work function is similar to that of $\mathrm{p}-\mathrm{Si}$, which cannot explain the photovoltage obtained in that work ( $460 \mathrm{mV})$. Detailed calculation of the band alignment after equilibrium with $\mathrm{H}^{+} / \mathrm{H}_{2}$ reaction should be supported considering doping concentration and Fermi level of the STO layer to describe exact charge transportmechanism.

Beside the above described silicon and III-V based photocathods, chalcopyrite-based thin film photocathode, e.g. p-type $\mathrm{Ag}_{x} \mathrm{Cu}_{1-\mathrm{x}} \mathrm{GaSe}_{2}$ (ACGSe), $\mathrm{CuGaSe}_{2}$ (CGSe), $\mathrm{Cu}(\mathrm{In}, \mathrm{Ga}) \mathrm{Se}_{2}$ (CIGSe), also have shown good HER stability, but mostly in weak acidic and alkaline media (Figure 5), because most chalcopyrite-based photocathodes are covered with a CdS layer, ${ }^{18,56,68}$ which is soluble in highly acidic and alkaline media. The CdS layer, which is ntype typically, plays a role as an electron transfer layer by forming pn-junction with the chalcopyrite layer, but not as a protection layer. Direct contact with a n-type $\mathrm{TiO}_{2}$ protection layer typically struggles to provide an efficient charge separation as shown by Azarpira et al. ${ }^{72}$ On the other hand, Ros et al. ${ }^{70}$ have coated a $\mathrm{TiO}_{2}$ overlayer as a protection layer on a CIGSe/CdS/i-ZnO/AZO multilayer structure and demonstrated efficient photocurrent output $\left(>40 \mathrm{~mA} \mathrm{~cm}{ }^{-2}\right.$ ) with a relatively high $V_{\text {on }}$ of $0.6 \mathrm{~V}$ vs. $\mathrm{RHE}$ in $0.5 \mathrm{M} \mathrm{H}_{2} \mathrm{SO}_{4}(\mathrm{pH} 0.3)$. Despite the recent progress in acidic electrolytes, continued work on protection property of $\mathrm{TiO}_{2}$ for the chalcopyritebased photocathodes in highly alkaline media is also needed, similar to the $\mathrm{TiO}_{2}$-protected silicon photocathode cases in highly alkaline media. ${ }^{13,34,79}$ 
Chem. Soc. Rev. 46, 1933-1954 (2017)

DOI: $10.1039 / \mathrm{c} 6 \mathrm{cs} 00918 \mathrm{~b}$
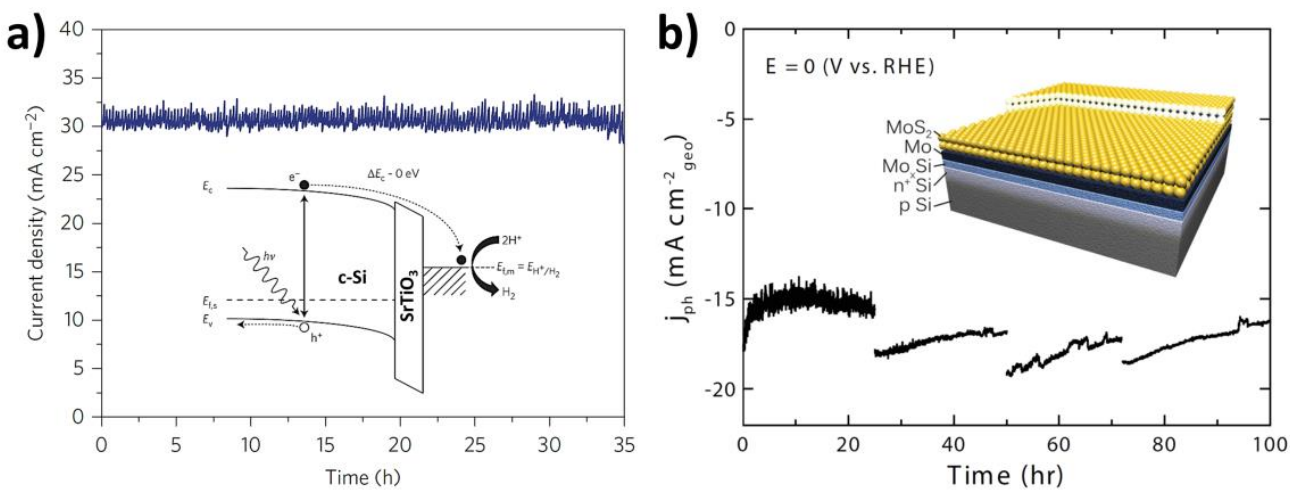

Figure 11. Stabilities as indicated by the steady-s ta te photocurrent cha racterization with c-Si/STO/Ti/Pt (a) (Reprinted with permission from ref. [48] Copyright 2016 Nature Publishing Group) and $\mathrm{pn}^{+}-\mathrm{Si} / \mathrm{Mo} / \mathrm{MoS}_{2}$ (b) (Adopted with permission from ref. [69] Copyright 2014 WILEY-VCH Verlag GmbH \& Co. KGaA, Weinheim) held at $0 \mathrm{~V}$ vs. Ag/Agd and RHE, respectively. Both tests were measured under $100 \mathrm{~mW} \mathrm{~cm}^{-2}$ illumination in $0.5 \mathrm{M} \mathrm{H}_{2} \mathrm{SO}_{4}(\mathrm{pH} 0.3)$. Schematic structures of the photocanode a re also shown in inset.

\subsection{Other layers}

Other protection layer candidates include carbon ${ }^{62}$ and the $\operatorname{MoS}_{x}$ family $y^{16,61,63,66,69,77,81}$ of materials. In this section, we focus on the latter group since this has shown some success when applied as cathode protection layers. $\mathrm{MoS}_{2}$ and some other di-chalcogenides have outstanding stability in strongly acidic electrolyte - even under above band-gap illumination. A recent study measured finite corrosion rates of $\mathrm{MoS}_{2}$ edges, but only under extremely intense laser illumination (corresponding to $10^{7}$ times the solar irradiance), and only when the photon energy was above the band-gap, and only when oxygen was present. ${ }^{93}$ In general though, $\mathrm{MoS}_{2}$ is an extremely durable material in a cathodic environment in very strongly acid electrolytes as shown experimentally in some studies (also shown in Fig. 11b), ${ }^{63,6981}$ but so far its use has been less widespread. Perhaps this is due to its two main disadvantages:i) limited conductivity perpendicular to the Mo $S_{2}$ planes and ii) significant optical absorption. $\mathrm{MoS}_{2}$ is a semiconductor with a band-gap in the red part of the spectrum such that optical absorption is an important consideration which means that the thickness of the $\mathrm{MoS}_{2}$ film should be minimized in any design where the $\mathrm{MoS}_{2}$-protected photocathode is facing the light source. If $\mathrm{MoS}_{2}$ is used on the backside with respect to the illumination, optical absorption is of course a non-issue, as mentioned earlier. ${ }^{2,10}$ Another reason to limit the thickness of an $\mathrm{MoS}_{2}$-based protection layer is that its electrical conductivity perpendicular to the 2D planes of $\mathrm{MoS}_{2}-$ i.e. its conductivity through the protection layer out to the electrolyte - is low. This means that the use of a thick (i.e. $50 \mathrm{~nm}$ ) $\mathrm{MoS}_{2}$ layer for electrode protection of the underlying photoabsorber would probably result in unacceptable loss of photovoltage due to the series resistance imparted by the protection layer. However, heavy doing (or strongly cathodic conditions) could shift 
the chemical potential enough to achieve much better electron transport, and we speculate that is why $\mathrm{MoS}_{2}$ protection layers work, but a detailed mechanism has not been studied fully.

$\mathrm{MoS}_{2}$ itself (if structured correctly) has the advantage of also being an excellent hydrogen evolution catalyst. ${ }^{94-}$ 97 This offers the compelling prospective of combining the function of protecting the photoabsorber from corrosion in the electrolyte with the function of providing electrocatalytically active sites for HER in the same, non-noble material. In conclusion, a thin $\mathrm{MoS}_{2}$ layer should be able to simultaneously achieve great chemical corrosion stability, moderate optical loss and Ohmic resistance, and comparatively good HER catalytic performance for a non-noble material in a concentrated acidic electrolyte.

In 2012, $\mathrm{MoS}_{2}$ (including amorphous $\mathrm{MoS}_{\mathrm{x}}{ }^{98}$ ) was used on a buried-junction $\left(\mathrm{pn}^{+}\right.$-Si) silicon photocathode in conjunction with a metallic titanium protection layer. ${ }^{38}$ This system showed promising performance, but its stability was erratic. Samples would run without apparent degradation on the order of a few hours (between 1 and 8 hours) before failing abruptly. The first use of $\mathrm{MoS}_{2}$ as a protection layer on a photocathode to achieve multi-day stability was in $2013 .^{63}$ In this case, an $\mathrm{MoS}_{2}$ - (or $\mathrm{WS}_{2}$ ) layer, grown by sputtering $10 \mathrm{~nm} \mathrm{Mo}$ (or W) directly on a buried-junction $\left(\mathrm{pn}^{+}\right.$-Si) silicon photocathodes was converted in a treatment with $\mathrm{H}_{2} \mathrm{~S} / \mathrm{H}_{2}$, and resulted in photocathodes where both protection and HER activation are derived from the resulting $\mathrm{MoS}_{2^{-}}$(or $W_{2}$ ) layer. ${ }^{63}$ While the $W_{2}$-protected photoelectrodes showed less than 20 hours stability and low photovoltage, the $\mathrm{MoS}_{2}$-protected photo electrodes worked remarkably well and showed no degradation after operating for 5 days. Besides the $\mathrm{MoS}_{2}$ protection and catalytic layer, a MoS $\mathrm{x}$ overlayer was also tested as a cocatalyst. $^{63}$ Almost exactly the same protection approach was taken by another group the following year with the main difference being a thinner sputtered Mo layer ( $3.6 \mathrm{~nm}$ instead of $10 \mathrm{~nm}$ ) and a correspondingly lower sulfurization temperature. ${ }^{69}$ In this case, the durability was tested for 100 hours - again with no signs of degradation, and with similar photoelectrode performance. In addition to the $\mathrm{MoS}_{2}$ protection layer, a $\mathrm{Mo}_{3} \mathrm{~S}_{13}{ }^{2-}$ cluster co-catalyst was also investigated in this work. ${ }^{69}$ Very recently the same group used the same method of sulfurizing a $3.6 \mathrm{~nm}$ sputtered Mo film to protect a $\mathrm{p}$-GaInP $\mathrm{P}_{2}$ photocathode. ${ }^{81}$ In this case they achieved $\sim 6 \mathrm{~mA} \mathrm{~cm}^{-2}$ of photocurrent (partially due to an estimated $40 \%$ of the photons above the band-gap of GalnP 2 being absorbed in the $\mathrm{MoS}_{2}$ film) and a stability of 60 hours followed by a decay, which they ascribe to pinholes in the protection layer. 
Chem. Soc. Rev. 46, 1933-1954 (2017)

DOI: $10.1039 / \mathrm{c} 6 \mathrm{cs} 00918 \mathrm{~b}$

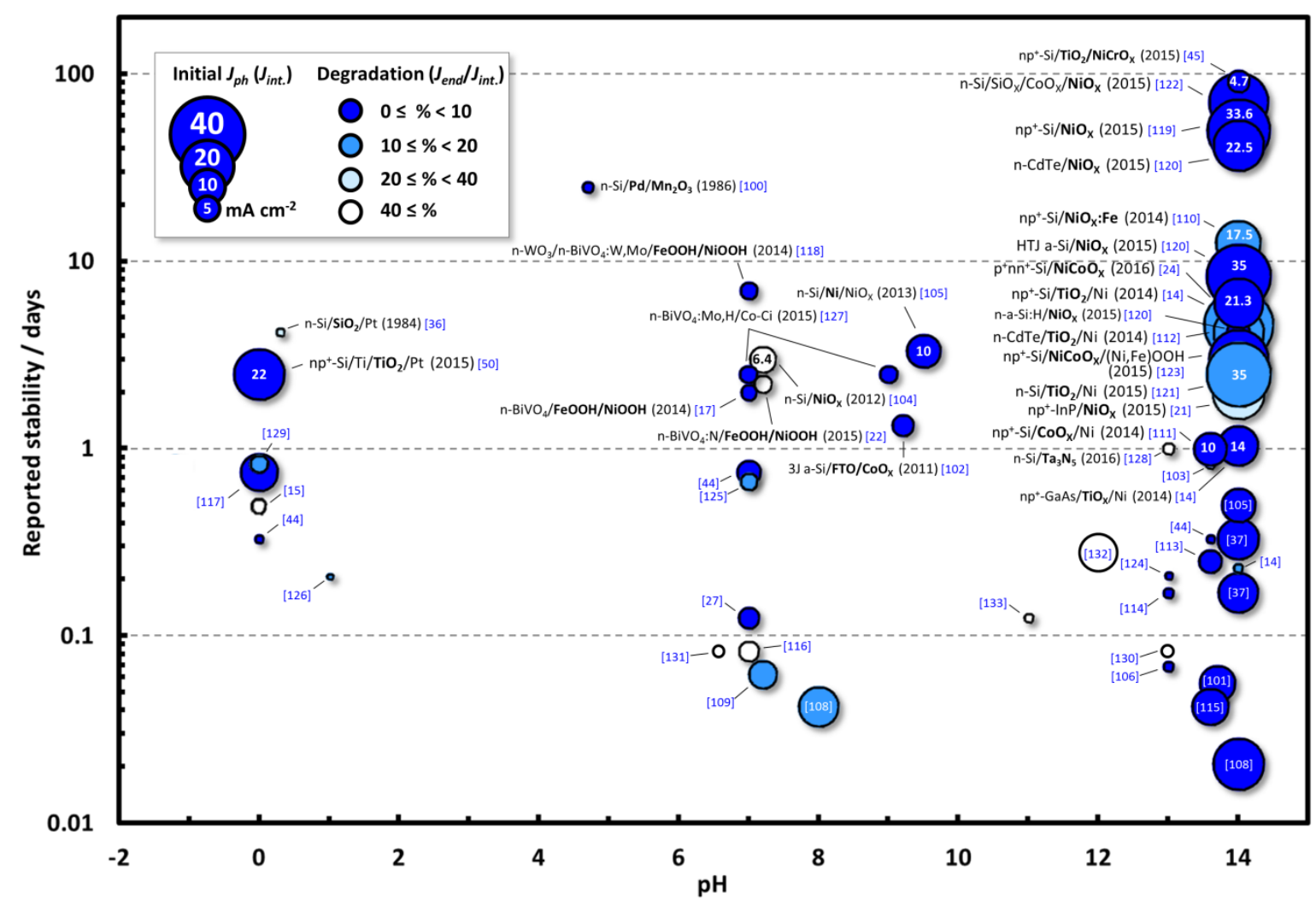

Figure 12. Chart visualizing data on reported stabilities of photocathodes for OER, versus $\mathrm{pH}$ of the test condition, illustrating photocurrent and degradation rate. Device structures for photoanode with reported stability longer than a da) a re noted. Detailed information on device structures working conditions a Iso can be found in Table S2 in ESIt.

In a tandem water splitting device design where the photoanode is facing irradiaction (top cell), the optical absorption of the cathodic protection layer is irrelevant as previously mentioned so the relevant questions are: can the stability be increased to 1000 s of hours - e.g., by the elimination of pinholes; and whether ultra-thin $\mathrm{MoS}_{2}$ layers with low Ohmic resistance can be stable for such a long term operation. It seems that the obvious research direction would be to make conformal coatings of $\mathrm{MoS}_{2}$ (for instance via ALD). While there are a large amount of oxides for protection layers that are currently being deposited with $\mathrm{ALD}^{99}$ to the best of our knowledge, there has yet to be tested an ALD-grown $\mathrm{MoS}_{2}$ or other sulfide protection layer on a photoelectrode.

\section{Protection of photoanodes}

Since Contractor et al. reported a reliably stable PEC water oxidation reaction for more than 4 days using $n$ type c-Si coupled with Pt in $0.5 \mathrm{M} \mathrm{H}_{2} \mathrm{SO}_{4}(\mathrm{pH} 0.3),{ }^{36}$ a variety of photoelectrodes have been used to develop photoelectrochemically stable water oxidizing photoanode systems as a counter part to the photocathode for the water splitting reaction. Just as in the photocathode case, considerable efforts have been made, as shown in Fig. 12, where data were collected from Ref. ${ }^{14,15,17,21,22,24,27,36,37,44,44,45,50,100-133}$ While there are many excellent 
HER catalysts (e.g., Pt, MoS $2, \mathrm{CoP}$ ), in contrast, there is a serious struggle to find acceptable OER catalysts in acidic environments. ${ }^{95}$ The majority of non-noble catalysts for OER suffer from deleterious degradation side reactions, particularly in the low $\mathrm{pH}$ region, ${ }^{134}$ where the bleaching of the electrocatalyst and loss of OER kinetics results. Unprotected non-oxide photoanode materials, on the contrary, oxidize under OER conditions by forming an insulating layer that potentially prevents decomposition of semiconductors during OER reaction. ${ }^{44}$ Only a few OER catalysts, including $\mathrm{IrO}_{\mathrm{x}}$ and $\mathrm{RuO}_{\mathrm{x}}$, are proven to be stable under acidic OER conditions, $^{117,135}$ and thus, significant attention has been devoted to protection of photoanodes in alkaline media as shown in Fig. 12.

Just as in the photocathode case shown in Fig. $5, \mathrm{TiO}_{2}$ has been widely used as an anodic protection layer. For instance, stable water oxidation reaction of $\mathrm{TiO}_{2}$ protected c-Si simply coupled with metallic OER catalyst, such as $\mathrm{Ni}$ and $\mathrm{Ir}$, were demonstrated in the $\mathrm{pH}$ range from 0 to $14 .^{14,44,112}$ However, the charge transport mechanism is quite different from that of the cathodic protection case, where the photo-induced carriers gen erally are injected through the conduction band of the n-type metal oxide protection layer. Several recent works have claimed hole-transfer via state-mediated (defect-state) transport (see also Fig. 4c) through a thick metal oxide layer from the photoanodes, ${ }^{14,107}$ while a majority of the works claimed hole injection via tunnelling for ultra-thin metal oxide cases. ${ }^{36,44,124}$ The detailed case study will be discussed in this section focusing on thin film protection materials for stable OER activity.

However, above all, p-type metal oxides, including $\mathrm{NiO}_{x}$ and $\mathrm{CoO}_{x}$, are most widely investigated, because they act as excellent hole-conducting protection layers, particularly in high $\mathrm{pH}$ conditions. This is because of their excellent hole-transfer and electron-blocking properties due to high CB edge positions. ${ }^{24,136-138}$ In addition, these transition metal oxides act as active OER catalysts by forming oxyhydroxides with higher oxidation states (via surface hydroxylation of the nickel or cobalt, e.g. $\mathrm{NiOOH}$ and $\mathrm{COOOH}$ ), which easily incorporate Fe during anodic reaction that reduces the overpotential for OER activity significantly. ${ }^{24,139,140}$ Thin metallic OER catalysts, including $\mathrm{Ni}$ and $\mathrm{Co}$, will also be discussed. Owing to the relative simplicity of the fabrication process compared to metal oxide, the protection strategy using a metallic layer is also widely used. However, unlike the HER cases, where the metallic layers tend to be reduced to metallic ions under cathodic condition, at high potentials, metallic OER catalysts form oxides and/or oxyhydroxides which are OER active sites. ${ }^{105,114,141}$

\subsection{Metal}


As opposed to the photocathode case for PEC hydrogen production in chapter 3.1 , the metals with a higher work function than the photoanode semiconductor can form a built-in potential by introducing a Schottkyjunction at the interface between the metal and the n-type semiconductor (see Fig. 6), which promotes separation and transport of the photo-induced charge carrier (holes in this case) to the electrolyte for water oxidation reaction. ${ }^{105}$ Kenny et al. reported in Ref. ${ }^{105}$ quite stable water oxidation performance using a 2-nmthick Ni coating on n-type c-Si in both aqueous $1 \mathrm{M} \mathrm{KOH}(\mathrm{pH} \mathrm{14)}$ and K-borate $+\mathrm{Li}$-borate electrolyte (pH 9.5) for more than 12 hours and 3 days, respectively. The key feature is formation of a MIS charge-separation structure by forming a native $\mathrm{SiO}_{2}$ insulating layer between the $\mathrm{n}$-type $\mathrm{c}-\mathrm{Si}$ and $\mathrm{Ni}$ metallic layer that provides a relatively high photovoltage of $\sim 500 \mathrm{mV}$. In addition, oxidized $\mathrm{Ni}$ species are formed at the $\mathrm{Ni}$ metal surface in contact with the electrolyte at oxidative potentials; they act as the OER active sites as mentioned earlier. Higher photovoltage is also obtainable without losing its PEC stability by adding a metal with high work function, such as Pt and Pd. ${ }^{101,100}$ Particularly, Kainthla et al. ${ }^{100}$ demonstrated outstanding OER stability under illumination for more than 25 days using a Pd coated n-type c-Si coupled with $\mathrm{Mn}_{2} \mathrm{O}_{3}$ as a co-catalyst. Although it showed low photocurrent output ( 1.4 mA cm-2 @ 1.3V vs NHE), the relatively high photovoltage ( $550 \mathrm{mV})$ performance is worthy of notice considering its publication time (1986) and relatively low pH condition ( 4.5). As described in the previous section, most metallic protection layers form metal oxides or oxyhydroxides under OER conditions, and thus further details are discussed in following metal oxide chapter for conciseness.

\subsection{Metal oxides}

When dealing with semiconductor protection layers they need to conduct charge, typically holes, with minimal resistive barrier. The resistive barrier includes both bulk resistance and resistance at the semiconductorelectolyte interface due to band bending.

$\mathrm{NiO}$ is a Mott-insulator, which means its band gap is primarily derived from a splitting between the d-orbitals. Thus both the $V B$ and $C B$ are a function of the temperature, and this makes NiO different from many other common oxides $\left(\mathrm{TiO}_{2}, \mathrm{WO}_{3}\right.$, etc.) whose band gap are primarily derived from a $\mathrm{VB}$ based on the $\mathrm{O} 2 \mathrm{p}$ orbital and a $\mathrm{CB}$ based on the metallic s-orbital. Since the VB of $\mathrm{NiO}$ is based on a d-orbital rather than the typical O2p orbital, it will typically be more reductive in potential. This is born out in experiments where NiO typically shows a valence band around $1.0 \mathrm{~V}$ vs. $\mathrm{RHE}^{136}$ whereas oxides such as $\mathrm{TiO}_{2}$ and $\mathrm{WO}_{3}$ show a valence band near 3.0 V vs. RHE. ${ }^{87}$ 

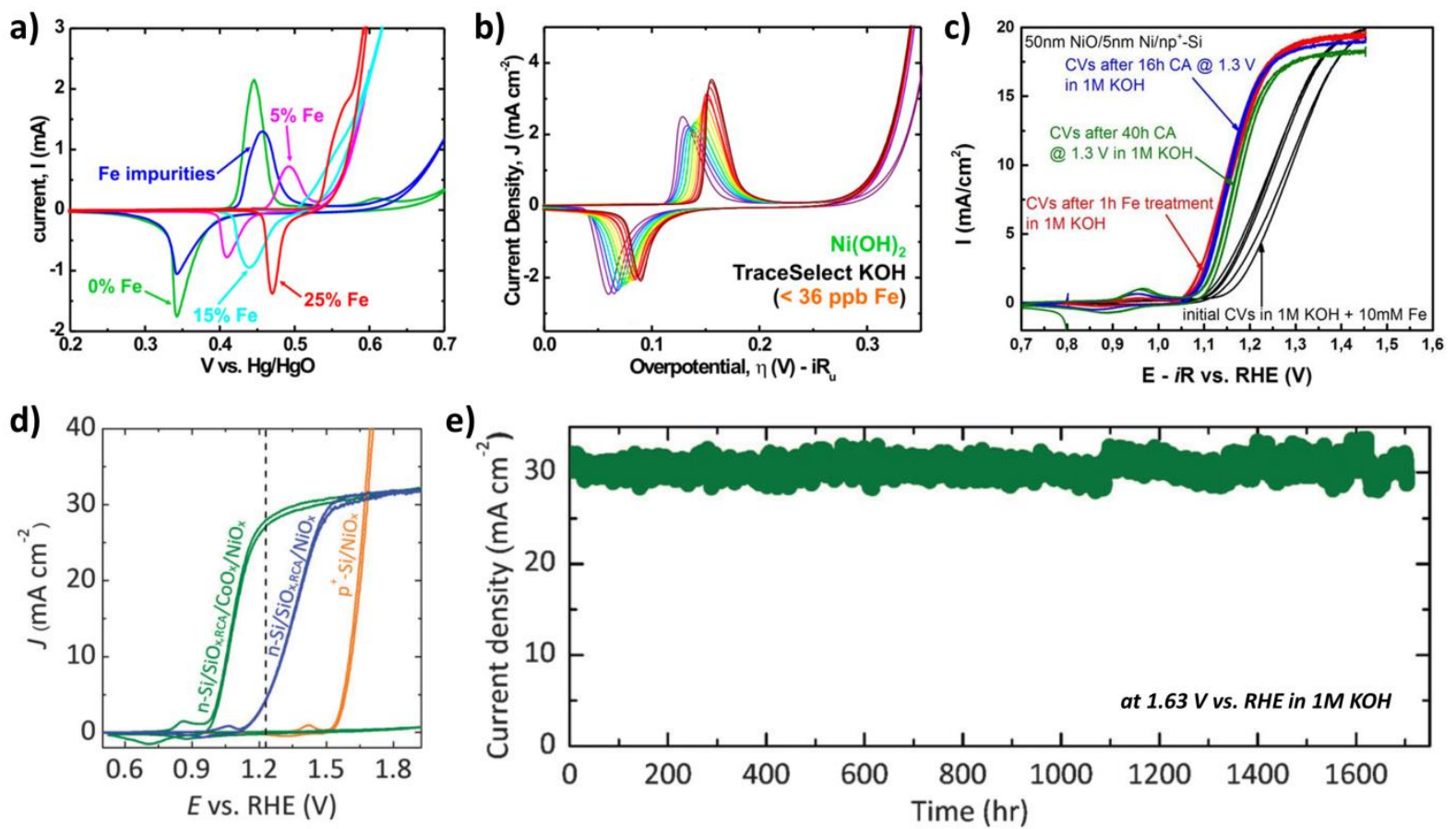

Figure 13. $\mathrm{CV}$ scans of $\mathrm{Ni}_{1-x} \mathrm{Fe}_{x}(\mathrm{OH})_{2} / \mathrm{Ni}_{1-\mathrm{x}} \mathrm{Fe}_{\mathrm{x}} \mathrm{OOH}$ films (a) and $\mathrm{CV}$ ta ken during 1 hour aging of $\mathrm{Ni}(\mathrm{OH})_{2}$ film (b) under dark condition in $1 \mathrm{M} \mathrm{KOH}$ containing low-ppm Fe $(<36 \mathrm{ppm})$. Reproduced with permission from ref. [144]. Copyright 2014 American Chemical Society. (c) CV curves of PEC measurements of Fe-treated NiO thin films on $\mathrm{np}^{+}$-Si photoanodes after various treatments under $38.6 \mathrm{~mW} \mathrm{~cm}^{-2}(\lambda \geq 635 \mathrm{~nm})$. Reprinted with permission from the American Chemical Society (ref. [114]). (d) $\mathrm{CVs}$ of $\mathrm{n}-\mathrm{Si} / \mathrm{SiO}_{x} / \mathrm{CoO}_{x} / \mathrm{NiO}_{x}, \mathrm{n}-\mathrm{Si} / \mathrm{SiO} \mathrm{O}_{x} / \mathrm{NiO} \mathrm{O}_{x}$ and $\mathrm{n}-\mathrm{Si} / \mathrm{NiO}_{\mathrm{x}}$ and (e) chronoamperometry (CA) of $\mathrm{n}$ $\mathrm{Si} / \mathrm{SiO}_{x} / \mathrm{CoO}_{x} / \mathrm{NiO}_{x}$ photoanodes measured at $1.63 \mathrm{~V}$ vs. RHE. Both experiments were carried under AM $1.5 \mathrm{G}$ sola il lumination. Reprinted with permission from the ref. [122] Published by The Royal Society of Che mistry.

Since $\mathrm{NiO}$ naturally acts as a p-type semiconductor, this material typically transfers charge through its valence band. Since the VB is located at a potential more reductive than the actual $\mathrm{O}_{2}$ evolution potential (thermodynamic potential + overpotential), there should be no resistance due to band bending since at these potentials there will actually be an accumulation layer or band de-pinning at the surface. However since NiO has a bulk resistance of $1.4 \times 10^{-4} \Omega \mathrm{cm},{ }^{142}$ it can produce noticeable resistance if the thickness is significantly large.

However with a wide band gap of 3.4-3.7 ev, ${ }^{109,137,143}$ a NiO protection layer basically does not absorb visible light from solar irradiation, and correspondingly, thin $\mathrm{Ni}$-based oxide layers $(30-50 \mathrm{~nm})$ show high optical transmittance above $90 \%$ in visible light region. ${ }^{104,110,119}$ In addition, NiO is quite stable in base, (though unstable in acid), and is also one of the best $\mathrm{O}_{2}$ evolution catalysts if doped with Fe, as shown in Fig. 13ac. $^{110,139}$

In 2012 Sun et al. started investigating NiO on n-Si for PEC devices. ${ }^{104}$ In this work they used NiO for three purposes, a protection layer, an $\mathrm{O}_{2}$ evolution catalyst (via forming $\mathrm{NiOOH}$ ) and as a material to create band bending and hence photovoltage within the $\mathrm{Si}$. Unfortunately, the onset potential for $\mathrm{O}_{2}$ evolution was very 
near the $\mathrm{H}_{2} \mathrm{O} / \mathrm{O}_{2}$ redox potential and currents were tested only up to $1 \mathrm{~mA} \mathrm{~cm}{ }^{-2}$. The photovoltage provided by the $\mathrm{n}-\mathrm{Si} / \mathrm{NiO}_{\mathrm{x}}$ was found to be on the order of $300 \mathrm{mV}$ under A.M 1.5 condition. The PEC experiments were done at neutral $\mathrm{pH}$, and there was little in-depth work into its durability. Further work using a $\mathrm{NiO} / \mathrm{RuO}_{\mathrm{x}}$ on nSi nanowires provided slightly better performance but showed significant degradation after 500 cycles. ${ }^{109}$ While low in photocurrent and photovol tage, these initial works unveiled the great potential of using NiO as a protection layer.

In $2014 \mathrm{Mei}$ et al. investigated a $\mathrm{pn}^{+}-\mathrm{Si} / \mathrm{Ni} / \mathrm{NiO}_{\mathrm{x}}$ structure for use in $\mathrm{PEC} \mathrm{O}_{2}$ evolution in alkaline conditions (1M $\mathrm{KOH}) .{ }^{110}$ Unlike the previous approach by Sun et al., ${ }^{104}$ they used a built-in Si homojunction to create band bending within the $\mathrm{Si}$. Since the $\mathrm{NiO}_{\mathrm{x}}$ was sputter deposited, a thin Ni layer was pre-sputtered onto the $\mathrm{Si}$ before the $\mathrm{NiO}$ to prevent silicon oxidation. When $\mathrm{NiOOH}$ is us ed as an $\mathrm{O}_{2}$ evolution catalyst (OEC), often times researchers allow very minute concentrations of Fe contaminants found naturally in their electrolyte (from impurities in $\mathrm{NaOH}$ or $\mathrm{KOH}$ ) to intercalate into the $\mathrm{NiOOH}$ to form the highly active $\mathrm{NiFeO}_{x}$ catalyst (Fig. 13c). In Ref. [110], however, they intentionally pre-intercalated Fe into their electrode before actual $\mathrm{O}_{2}$ evolution, which allowed them to achieve optimal performance directly from the beginning of their water splitting experiments. This approach allowed for an anodic photocurrent of $10 \mathrm{~mA} \mathrm{~cm}{ }^{-2}$ at a potential of $1.15 \mathrm{~V} v \mathrm{Vs}$. RHE. Furthermore they showed this material to be stablein a basic environment for 2 weeks with only minimal signs of degradation. Through analysis of the electrolyte after 24 hours of testing, they determined (through inductively coupled plasma (ICP) analysis) that their $\mathrm{NiO}_{x}$ was corroding at a rate of between $0.06-0.08$ monolayers per day, which corresponds to approximately 2,800 days or 7.6 years of continuous operation to fully corrode.

Very shortly after the Mei work, Sun et al. showed a very similar system and demonstrated stability for 50 days. $^{119}$ They compared their NiO protection layer to a thin Ni metal layer, and showed that NiO acts as an anti-reflection layer in addition to a protection layer. Following the same approach NiO was shown also to work as an excellent protection layer for an InP photoelectrode comprising a $\mathrm{np}^{+}-\mathrm{InP} / \mathrm{NiO}$ electrode. ${ }^{21} \mathrm{This}^{\mathrm{n}}$ device produced $10 \mathrm{~mA} \mathrm{~cm} \mathrm{O}_{2}$ evolution current at a potential of $1.0 \mathrm{~V}$ vs. RHE and was shown to be stable for at least 48 hours.

While the work by Sun et al. that used a $\mathrm{NiO}$ to induce band bending in $\mathrm{Si}$ only produced $\sim 300 \mathrm{mV}$ of photovoltage, switching to $\mathrm{CoO}_{\mathrm{X}}$ led to $560 \mathrm{mV}$ photovoltage during $\mathrm{O}_{2}$ evolution (and $640 \mathrm{mV}$ photovoltage when using a ferrocene redox couple) (see also Fig. 13a). ${ }^{122}$ This work used only $2-3 \mathrm{~nm}$ of $\mathrm{CoO}_{\mathrm{x}}$ to induce a 
MIS-like charge separation by forming $\mathrm{c}-\mathrm{Si} / \mathrm{SiO} / \mathrm{CoO}$ and they were still able to deposit a thick NiO layer ( 85 $\mathrm{nm}$ ) on top of it with no detrimental effects to its transparency or its ability to protect for more than 70 days under continuous light-illumination.

Besides the $\mathrm{c}-\mathrm{Si}$ cases described above, recent studies have revealed that the protection strategy using $\mathrm{Ni}$ based metal oxides can be applied effectively to various thin-film semiconductors, such as a-Si:H, CdTe ${ }^{120}$ and $\mathrm{Ta}_{3} \mathrm{~N}_{5} \cdot{ }^{128}$ Thin film metal-oxide photoanodes, particularly $\mathrm{BiVO}_{4}$-based photo electrodes also showed noticeable OER stability. Various oxyhydroxides, e.g. electrodeposited $\mathrm{NiOOH}$ and $\mathrm{FeOOH},{ }^{17,22,118,125}$ have been applied to the $\mathrm{BiVO}_{4}$ as protecting OER catalysts, however, most of those studies are limited to neutral pH (Figure 12), mainly due to photoelectrochemical corrosion of the $\mathrm{BiVO}_{4}$ in highly alkaline media. ${ }^{114}$ Lichterman et al. ${ }^{106}$ demonstrated that a thin $\mathrm{ALD} \mathrm{COO}_{\mathrm{X}}$ coated $\mathrm{BiVO}_{4}$ shows significantly improved OER stability in $0.1 \mathrm{M} \mathrm{KOH}(\mathrm{pH}$ 13) indicating that the fabrication method is of great importance just as in the case of photocathode described above in the section 3.2 .

Cobalt-based oxide materials are also a widely used protection layers for photoanodes with a quite high resistance to photocorrosion. Similar to $\mathrm{Ni}$-based oxide materials, $\mathrm{CoO}_{\mathrm{X}}$ is also known to be oxidized and form oxyhydroxides, for instance $\mathrm{CoOOH}$, that easily incorporates Fe from the electrolyte easily. ${ }^{140}$ Interestingly, time-dependent behaviour in OER activity varies with reports. Bae et al. and other group reported gradual decrease of OER activities of $\mathrm{CoO}_{\mathrm{x}}\left(\mathrm{CoO}, \mathrm{CO}_{2} \mathrm{O}_{3}, \mathrm{Co}_{3} \mathrm{O}_{4}\right.$ mixed phase) coupled c-Si photoanodes in their recent works, ${ }^{24,122}$ while Yang et al. ${ }^{111}$ reported very stable OER activities under same condition $(1 \mathrm{M} \mathrm{KOH}, \mathrm{pH} 14)$ using an $\mathrm{np}^{+}-\mathrm{Si} / \mathrm{CoO}_{\mathrm{x}}$ photoanode. In regards to this, several works on pure electrochemical stabilities of cobalt oxide can provide a clue to understand this discrepancy. Burke et al. ${ }^{140}$ demonstrated a gradual enhancement of OER activity in $\mathrm{KOH}$ electrolyte due to the iron-incorporation in $\mathrm{CoOOH}$ formed by the electrodeposition method. Jiang et al. ${ }^{144}$ also reported a quick decrease in overpotential for OER of the electrodeposited CoOOH for the first 2 min., followed by stable OER activity for more than 10 hours. Tung et al. ${ }^{145}$ revealed in their recent work that $\mathrm{Co}_{3} \mathrm{O}_{4}$ tends to decompose gradually under water oxidation condition, whereas $\mathrm{CoO}$ supported $\mathrm{CO}_{3} \mathrm{O}_{4}$ showed very stable OER activity for 1,000 hours under the same condition, indicating that stability of $\mathrm{CoO}_{x}$ phase is related with volume expansion during the phase transformation to $\mathrm{CoOOH}$.

While there has been great interest in using $\mathrm{TiO}_{2}$ as a photoanodic protection layer since the 2014 work of $\mathrm{Hu}$ et al., ${ }^{14}$ there has actually been some very significant works investigating $\mathrm{TiO}_{2}$ in a photoanodic environment before the Hu work. In 1977 Tomki ewicz et al. ${ }^{146}$ investigated the corrosion protection ability of TiO ${ }_{2}$ on n-type 
Chem. Soc. Rev. 46, 1933-1954 (2017)

DOI: $10.1039 / \mathrm{c} 6 \mathrm{cs} 00918 \mathrm{~b}$

a)

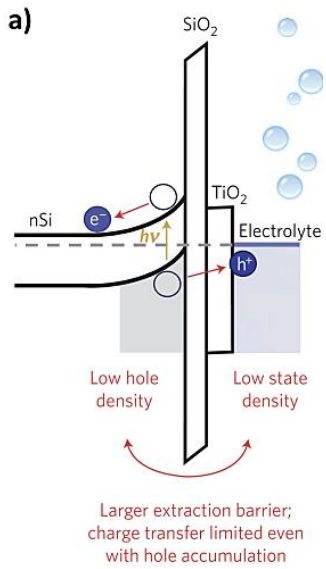

b)

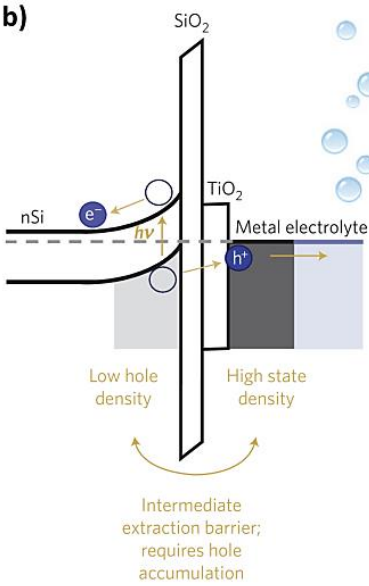

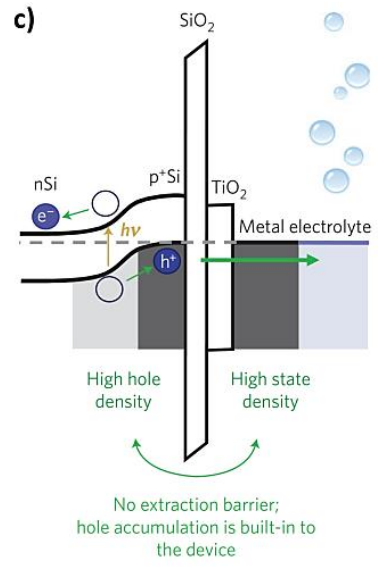

Figure 14. Three types of photoanode junctions have been employed in the ref. [156]: (a) semiconductor-liquid junction protected by $\mathrm{SiO}_{2}$ and $\mathrm{TiO}_{2}$, (b) MIS structure with metallic OEC, and (c) MIS with buried np ${ }^{+}$-junction. Here, the holes are tra ns ported via defect s tates of $\mathrm{TiO}_{2}$. Re printed wi th permission from ref. [156] Copyright 2016 Na ture Publishing Group.

semiconductors; however they only investigated the mechanical degradation and did not focus on the electrical conduction through $\mathrm{TiO}_{2}$. In 2011 Chen et al., used $\mathrm{TiO}_{2}$ as a corrosion protection layer for a $\mathrm{Si}$ photoanode with a thin film of Ir as a catalyst. ${ }^{44}$ The Chen work used an MIS structure to create photovoltage from their Si photoanode. They used the difference between the Fermi level in the $\mathrm{n}$-Si and the Ir work function to induce band bending within the Si. The insulator in the MIS structure was a combination of a thin $\mathrm{SiO}_{2}$ and the aforementioned $\mathrm{TiO}_{2}$ protection layer. The authors hypothesized that charge was transferring though the $\mathrm{TiO}_{2}$ via a trap assisted tunneling (Frenkel-Pool conduction) $)^{147,148}$ and in a later work showed a more detailed verification of this mechanism using various types of c-Si based photoanodes, including hybrid type MIS with buried $\mathrm{pn}^{+}$-junction (Fig. 14), which showed a photovoltage above $600 \mathrm{mV} .^{154}$

In the 2013 work by Seger et al. ${ }^{43}$ where they showed $\mathrm{TiO}_{2}$ as a cathodic protection layer, they also showed that it worked as a protection layer in an anodic environment. ${ }^{43}$ While the anodic reactions in this work were $\mathrm{H}_{2}$ oxidation, and oxidation of $\mathrm{Fe}^{2+}$ to $\mathrm{Fe}^{3+}$ the science discovered in this work provided the fundamental basis for further studies in anodic $\mathrm{O}_{2}$ evolution (Fig. 15). There wer e three interesting discoveries from the Ref. ${ }^{43}$ : the first was that while $\mathrm{pn}^{+} \mathrm{Si}$ electrodes have a band bending that favours electrons diffusing to the surface for reductive reactions, this work showed these types of electrodes can also achieve oxidative reactions. Simply put, the anodic charge coming from oxidized reactants at oxidative potentials would have occurred from band bending. The actual electrons that were oxidized from the reactants travelled through a $\mathrm{TiO}_{2}$ and $\mathrm{Ti}$ layer into the Si conduction band where they recombined with holes in the silicon valence band. It should be noted that these holes were not primarily generated by photons, but rather valence band electrons that were extracted 
Chem. Soc. Rev. 46, 1933-1954 (2017)

DOI: $10.1039 / \mathrm{c} 6 \mathrm{cs} 00918 \mathrm{~b}$

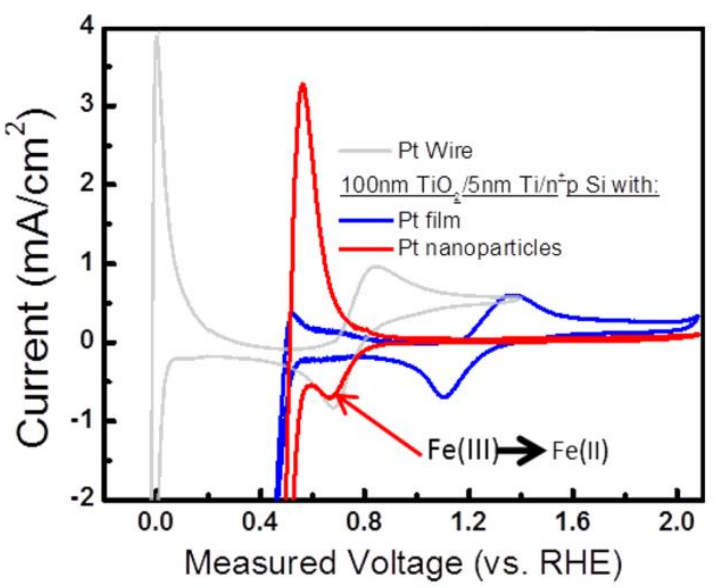

Figure 15. $\mathrm{CV}$ scans of a $\mathrm{pn}^{+}-\mathrm{Si} / \mathrm{Ti}_{1} / \mathrm{TiO}_{2} / \mathrm{np}$-Pt electrode in an a rgon-purged $1 \mathrm{M} \mathrm{HClO}_{4}$ electrol yte with $10 \mathrm{mM}$ each of $\mathrm{Fe}$ (III) and $\mathrm{Fe}(\mathrm{II})$. The scan rate was $20 \mathrm{mV} / \mathrm{s}$ and the samples were irradiated with the red part $(\lambda>635 \mathrm{~nm})$ of the AM1. spectrum. Reprinted with permission from Ref. 43. Copyright (YEAR) American Chemical Society

via the electrode (for use in the counter electrode). This allowed the device to maintain its photovoltage even as the oxidation reaction was occurring.

The second interesting issue is related to $\mathrm{TiO}_{2}$ 's band position. Given that $\mathrm{TiO}_{2}$ 's band position is near the $\mathrm{H}^{+} / \mathrm{H}_{2}$ redox couple, the authors showed that $\mathrm{H}_{2}$ could be oxidized whereas band bending issues prevented $\mathrm{Fe}^{2+} / \mathrm{Fe}^{3+}$ oxidation (unless the $\mathrm{TiO}_{2}$ was so highly doped it allowed for tunnelling). ${ }^{47}$ However it was shown that the $\mathrm{H}_{2}$ oxidation could continually occur even at potentials more oxidative than the $\mathrm{Fe}^{2+} / \mathrm{Fe}^{3+}$ redox couple. The fact that $\mathrm{H}_{2}$ could oxidize at highly oxidative potentials, whereas $\mathrm{Fe}^{2+}$ could not, was attributed to the fact that the band bending within the $\mathrm{TiO}_{2}$ caused a large potential drop within the semiconductor and that the actual oxidative potential of the $\mathrm{TiO}_{2}$ at the semiconductor-electrolyte interface was only slightly more oxidative than the $\mathrm{TiO}_{2}$ flat band potential.

The third interesting discovery from this work was the effects of sputtering a Pt film on top of the $\mathrm{TiO}_{2}$ protected Si photoelectrode. In doing so, this completely isolated the $\mathrm{TiO}_{2}$ from the electrolyte. This in turn eliminated any band bending due to the $\mathrm{TiO}_{2}$-electrolyte interface. However the $\mathrm{TiO}_{2}$-electrolyte interface was replaced by a $\mathrm{TiO}_{2}$-Pt interface, and it was unknown whether this would act as a Schottky barrier or an ohmic contact. When this Pt covered electrode was tested, it showed results similar to a Pt wire (except for the photovoltage shift) with the ability to both reduce $\mathrm{Fe}^{3+}$ and oxidize $\mathrm{Fe}^{2+}$, thus indicating this was an ohmic contact. Typically the $\mathrm{TiO}_{2}$-Pt interface forms a Shottky-barrier, however the high dopant density of $\mathrm{TiO}_{2}$ and the high energy of Pt sputtering into the $\mathrm{TiO}_{2}$ could be potential reasons for this Ohmic contact. The practical results of these oxidation tests showed that one can basically bury a solar cell and $100 \mathrm{~nm}$ of $\mathrm{TiO}_{2}$, and it would behave equivalently as a solar cell in series with a conductive electrode. However this was only the case when 
two very important parameters were met: 1) The semiconductor-electrolyte interface was removed and 2) $\mathrm{TiO}_{2}$-Ptformed an Ohmic contact.

With this in mind, it was straightforward to apply this principle to using $\mathrm{TiO}_{2}$ as an anodic protection layer for $\mathrm{O}_{2}$ evolution. After the Hu et al. work demonstrated that Leaky $\mathrm{TiO}_{2}$ could be used as a photoanodic protection layer for $\mathrm{O}_{2}$ evolution (vide infra), in the work by Mei et al. they used the same approach as in the Seger et al. ${ }^{43}$ work, with this time using a $\mathrm{pn}^{+}-\mathrm{Si}$ with a sputtered $\mathrm{Ti} / \mathrm{TiO}_{2} / \mathrm{Pt}$ film, and they could indeed oxidize water to $\mathrm{O}_{2}{ }^{50}$ It should be noted that only sputtered Pt worked using this approach whereas evaporated Pt failed. This was hypothesized to be due to high energy impact from the sputtering process creating interfacial states thus allowing it to act more as an Ohmic contact rather than a Schottky barrier. ${ }^{150,151}$ This work also investigated the $\mathrm{n}^{+} \mathrm{Si} / \mathrm{Ti}$ (or more probably $\left.\mathrm{n}^{+} \mathrm{Si} / \mathrm{TiSi}_{\mathrm{x}} / \mathrm{Ti}\right)^{152}$ interface and showed both theoretically and experimentally that at high Si dopants levels charge could tunnel through the barrier created by the $\mathrm{Si}_{-} \mathrm{TiSi}_{\mathrm{x}}$ Schottky barrier, whereas at low dopant densities charge could not tunnel through this barrier. This charge transport mechanism is well illustrated in Fig. 16.

While using a Pt film/ $/ \mathrm{TiO}_{2}$ worked as an anodic protection layer, the Pt was actually interfacing with the electrolyte and was the primary protection layer. Creating a continuous film is an inefficient use of a catalytic material, especially one as expensive as Pt, but using nanoparticle catalyst will typically not work due to semiconductor band bending issues. However the intermediate case of small diameter islands of catalysts provides a very useful intermediate case. To understand how catalyst islands perform, one need to understand the fundamental concepts developed by Tung et al. and the work Robert Rossi and Nathan Lewis did applying this principle to mixed barrier heights at the semiconductor-electrolyte interface. ${ }^{153-155}$ In the Rossi and Lewis work they investigated the semiconductor/electrolyte interface of Si with evaporated Ni islands on the surface. In this situation there was a partial Si/electrolyte interface, which produced band bending, and a partial Si-Ni interface, which had a Schottky barrier. Through careful analysis they discussed the interaction between the semiconductor-electrolyte interface and the semiconductor-metal interface as a function of varying sizes of $\mathrm{Ni}$ islands. They showed that with very large $\mathrm{Ni}$ islands the $\mathrm{Si} / \mathrm{Ni}$ interface behaved as a Schottky barrier, however as the size of the islands decreased, the effects of band bending from the Si/electrolyte interface actually started to creep in on the edges of the $\mathrm{Ni}$ islands. They showed that when $\mathrm{Ni}$ islands were below a certain diameter, the band bending would creep in from all sides and deep within the bulk the band bending potential 

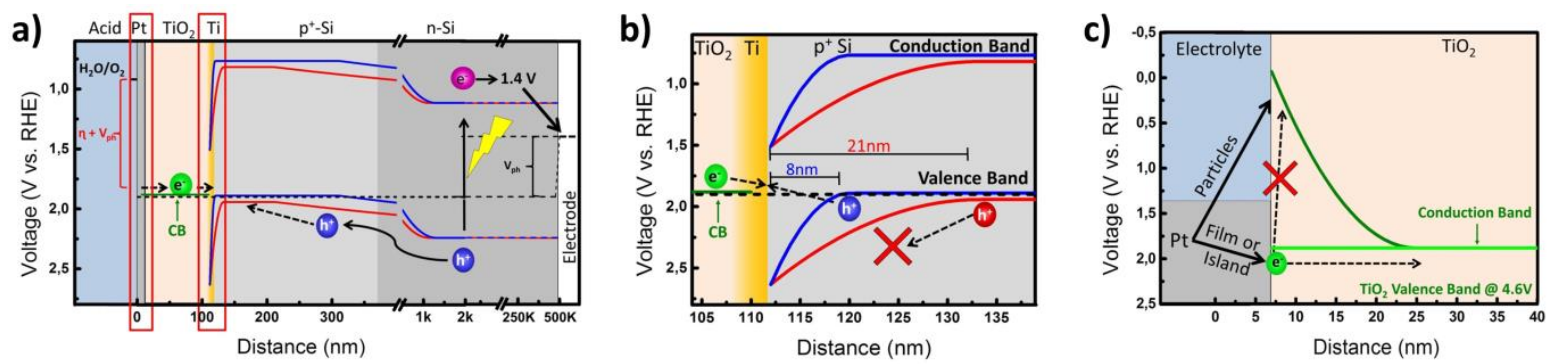

Figure 16. Band diagrams of an $\mathrm{np}^{+}-\mathrm{Si} / 5 \mathrm{~nm} \mathrm{Ti} / 100 \mathrm{~nm} \mathrm{TiO} / 2 / \mathrm{Pt}$ Film Photoelectrode: (a) Ove rall band diagram at an applied Bias of $1.4 \mathrm{~V}$ versus RHE under Illumination; (b) Zoom in of the $\mathrm{p}^{+}-\mathrm{Si} / \mathrm{Ti}$ Interface; (c) Zoom in of the $\mathrm{TiO}_{2} / \mathrm{Pt} /$ electrolyte Interface from the overall band diagram shown in (a). Reproduced with permission from ref. [51]. Copyright (2015) American Chemical Society

would completely dominate, thus effectively 'pinching-off' the Schottky-barrier. Theoretical modeling allows one to determine the radius below which the pinch-off effect occurs as:

$$
R_{0}<\frac{\left(\Phi_{E l e c}-\Phi_{\text {Island }}\right) W}{V_{B B}} \quad \text { Eq. } 1
$$

Where $R_{o}$ is the radius of the island, $\Phi_{\text {Elec }}$ and $\Phi_{\text {sland }}$ are the potential barrier between $\mathrm{Si}$ and the electrolyte and the island, respectively. $W$ is the depletion width and $V_{B B}$ is the voltage due to band bending.

The pinch-off effect is also very useful because it is a very straightforward explanation of why co-catalysts attached to photocatalysts al most never show any effects of a Schottky-barrier. Hill et al. has recently found a way to exploit this concept by using it to greatly enhance the photovoltage of $\mathrm{n}$-Si-/Co interfaced devices. ${ }^{156}$ In their work they showed that by electrodepositing Co islands they could pinch off the Si/Co electronic effects, and still use the dominant Si/electrolyte interface to achieve band bending and thus a high photovoltage. They followed this experiment up by showing that if the electrodeposited Co became a film this mitigated the Sielectrolyte interface and thus creating a Schottky barrier, which in turn, lowered the photovoltage.

On the other hand, however, Equation 1 shows that if the depletion width is small (as in the case of a highly doped semiconductor), the metal islands can actually be quite small and still maintain the electronic effects of the semiconductor-metal interface. This approach of creating small catalyst islands has been used in many instances including the aforementioned work by Mei et al. ${ }^{50}$ Since the Mei work had already shown that a $\mathrm{TiO}_{2} /$ sputtered Pt film formed an Ohmic contact (see Fig. 16c), when they sputter ed Pt catalyst islands on the $\mathrm{TiO}_{2}$, the catalysts still maintained the Ohmic contact thus allowing for $\mathrm{O}_{2}$ evolution to occur. Interestingly, the Pt nanoparticles $(\sim 5 \mathrm{~nm})$ coated electrode case (Fig. 16c) showed a significant resistance in the Mei work ${ }^{50}$ when it is used for OER, while there was no problems for the $\mathrm{TiO}_{2}$ coated Si photocathodes which were coated 

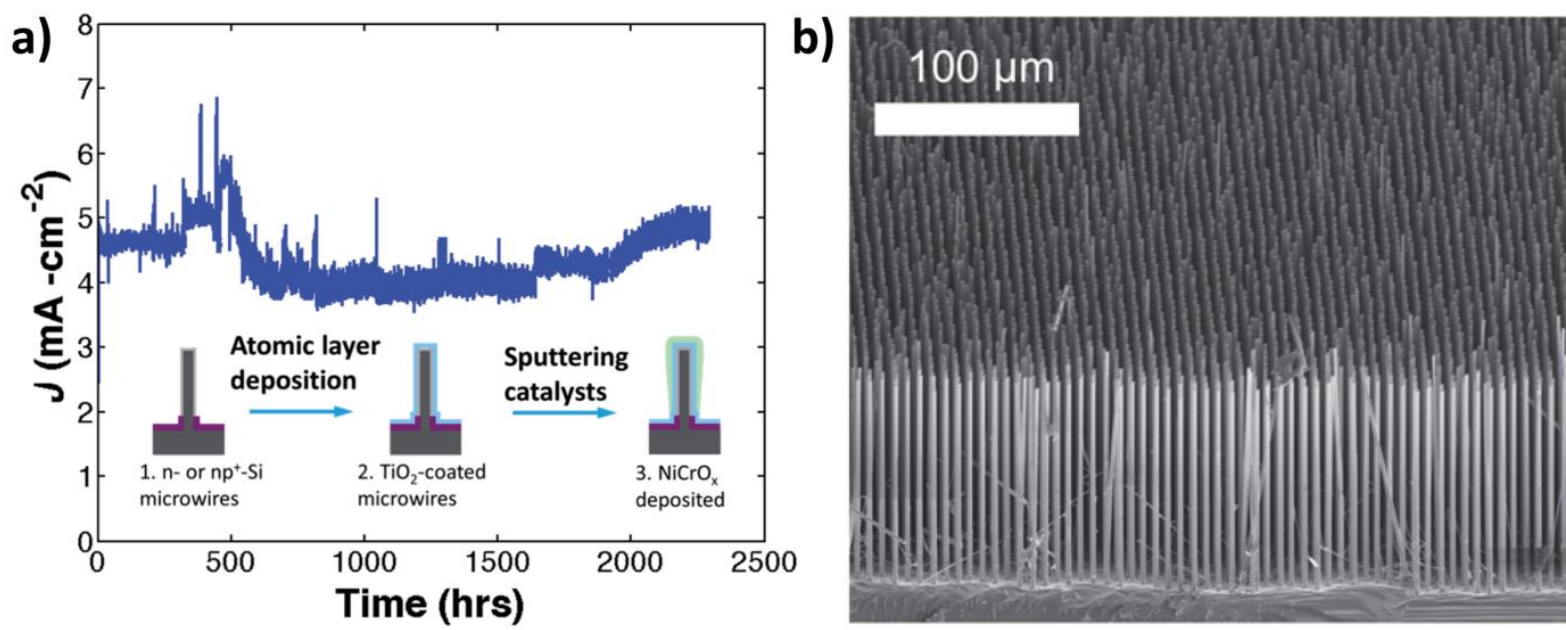

Figure 17. (a) $\mathrm{CA}$ for an $\mathrm{np}^{+}-\mathrm{Si} / \mathrm{TiO}_{2} / \mathrm{NiCrO}_{\mathrm{x}}$ microwire-a rray photoelectrode under 1 Sun simulated illumination in $1.0 \mathrm{M}$ $\mathrm{KOH}(\mathrm{pH} 14)$ at $0.36 \mathrm{~V}$ vs. $\mathrm{E}\left(\mathrm{OH}^{-} / \mathrm{O}_{2}\right)$. Schematic of a structure with fabrication procedure is added as inset. (b) SEM image of a fully processed microwire array. Re produced by permission from Ref. [45] of The Royal Society of Che mistry.

by Pt nanoparticles with similar sizes..$^{2,34,50,157}$ This can be explained by the aforementioned Schottky barrier at the Pt- $\mathrm{TiO}_{2}$ due to the pinch-off effect.

Of recent works, the McIntyre group was the first to investigate $\mathrm{TiO}_{2}$ as an $\mathrm{O}_{2}$ evolution protection layer, ${ }^{44}$ the Chorkendorff group was the first to investigate conduction through $\mathrm{TiO}_{2}$ in anodic environments, but the Lewis group was the first to actually show conduction through thick $(>10 \mathrm{~nm}) \mathrm{TiO}_{2}$ for photoanodic $\mathrm{O}_{2}$ evolution. Additionally their method for transferring charge through the $\mathrm{TiO}_{2}$ was much more ground breaking that the aforementioned approach used by the Chorkendorff group.

In the work by Hu et al., the Lewis group worked to create defect states throughout the an amorphous $\mathrm{TiO}_{2}$ which they referred to as 'Leaky $\mathrm{TiO}_{2}{ }^{\prime}{ }^{14}$ These defects states were located midway between the valence and conduction band and thus provided a path to allow charge to transfer at potentials near the $\mathrm{O}_{2}$ evolution potential, as described earlier in chapter 2.2. This charge was then transferred to small catalytic islands on which $\mathrm{O}_{2}$ was evolved. The semiconductor-catalyst interface appeared to be Ohmic for both evaporated and sputtered $\mathrm{Ni}$, but there appeared to be significant resistance, possibly from a Schottky barrier when Ir was deposited. The Leaky $\mathrm{TiO}_{2}$ has been shown to be effective on a wide variety of semiconductors such as planar and microwire $\mathrm{Si}, \mathrm{GaAs}, \mathrm{GaP}, \mathrm{CdTe} .^{14,45,112}$ Particularly, a leaky $\mathrm{TiO}_{2}$ protected NW np ${ }^{+}-\mathrm{Si}$ with $\mathrm{NiCrO}_{\mathrm{x}}$ OEC layer demonstrated in Ref. ${ }^{45}$ has shown a record long-term stability in OER so far (Fig. 16). The 'Leaky $\mathrm{TiO}_{2}$ ' was quite an unusual result, thus there were many questions regarding that. The 2016 follow up work by Hu et al. investigated the energy locations of the various states in a $\mathrm{Si} /$ leaky $\mathrm{TiO}_{2}$ heterojunction and did a thorough job of investigating many of these questions. ${ }^{158}$ Through a variety of techniques they showed a comprehensive 
energy band diagram of the $\mathrm{n}$-Si/leaky $\mathrm{TiO}_{2}$ heterojunction with either a $\mathrm{SiO}_{2}$ or $\mathrm{Si}_{x} \mathrm{Ti}_{y} \mathrm{O}_{z}$ interface. They also showed that this $\mathrm{n}-\mathrm{Si} /$ leaky $\mathrm{TiO}_{2}$ could induce a $390 \mathrm{mV}$ open circuit voltage. Man et al. investigated a very similar system using both $\mathrm{n}$-Si/amorphous $\mathrm{TiO}_{2}$ as well as $\mathrm{p}$-Si/amorphous $\mathrm{TiO}_{2}$ for photovol taic applications. ${ }^{159}$ In their study the $\mathrm{TiO}_{2}$ did not act as a hole conducting layer, but rather a hole blocking layer. However they deposited $\mathrm{TiO}_{2}$ via a CVD method at $100^{\circ} \mathrm{C}$ rather than an $\mathrm{ALD}$ at $150^{\circ} \mathrm{C}$, which strongly hints that the exact deposition procedure is essential to create this Leaky $\mathrm{TiO}_{2}$.

One of the more interesting follow up works on the Leaky $\mathrm{TiO}_{2}$ was the work by McDowell et al, where they showed that a sputtered $\mathrm{TiO}_{2}$ without significant mid gap defect states could also achieve anodic conductivity to evolve $\mathrm{O}_{2} \cdot{ }^{121}$ The McDowell et al. work by the Lewis group and the Mei et al work by the Chorkendorff group used the same sputtering $\mathrm{TiO}_{2}$ technique for anodic conductivity, but unfortunately the both were published at almost the same time, thus neither of these works could mimic and compare to the other approach. However there are still some unresolved issues with Leaky $\mathrm{TiO}_{2}$ such as exactly how charge conducts through the $\mathrm{TiO}_{2}$. Both DFT calculations ${ }^{160}$ and experimental results ${ }^{161}$ have shown that oxygen vacancies can allow for deep level trap sites as those found in the Leaky $\mathrm{TiO}_{2}$. However calculations by Lewerenz show that the charge transfer was probably not due to a Poole-Frenkel type mechanism. ${ }^{162}$ While the Lewis group has shown amorphous 'Leaky' $\mathrm{TiO}_{2}$ to be highly conductive to charge, the Mclntyre's group has shown that their amorphous $\mathrm{TiO}_{2}$ creates a barrier for conduction of charge. ${ }^{148}$ While both their ALD processes appear quite similar, small difference must account for the discrepancies and further studies are needed to clarify this situation.

With the exception of the previously described Si-based photoanodes, very limited number of studies has reported meaningful OER stabilities in acidic solutions. ${ }^{14,131,134} \mathrm{Li}$ et al. coated a thin $\operatorname{IrO}_{\mathrm{X}}$ on the hematite $\left(\mathrm{Fe}_{2} \mathrm{O}_{3}\right)$ photoanode and showed a stable PEC activity under OER conditions in adjusted $\mathrm{HNO}_{3}$ with $0.1 \mathrm{M} \mathrm{KNO}$ $(\mathrm{pH} 1.01)$ for 5 hours. Although $\mathrm{IrO}_{x}$ coated $\mathrm{Fe}_{2} \mathrm{O}_{3}$ showed $5 \%$ photocurrent loss after the stability test, this is of significance because it was the first demonstration of OER using hematite in highly acidic solutions. Recently, Sarnowska et al. ${ }^{129}$ also demonstrated stable OER in $1 \mathrm{M} \mathrm{CH}_{3} \mathrm{SO}_{3} \mathrm{H}(\mathrm{pH} \approx 0)$ for 20 hours using sodium doped $\mathrm{WO}_{3}$ without any co-catalyst and protection layer. However, as described above in the introduction part, the high $E_{g}$ of $\mathrm{WO}_{3}(\sim 2.5 \mathrm{eV})$ fundamentally limits the light absorption and leads to poor photocurrent 
Chem. Soc. Rev. 46, 1933-1954 (2017)

DOI: $10.1039 / \mathrm{c} 6 \mathrm{cs} 00918 \mathrm{~b}$

performance $\left(\sim 3 \mathrm{~mA} \mathrm{~cm}{ }^{-2}\right)$. On the other hand, this implies that $\mathrm{n}-\mathrm{WO}_{3}$ could potentially be used as a protection layer for highly acidic conditions rather than as a light absorber material.

\subsection{Other layers}

In general, tantalum oxynitride (TaON) has a sufficiently wide band-gap $(\sim 2.4 \mathrm{eV})^{163}$ with suitable band alignment for both water oxidation and reduction, but it is also known to undergo deterioration in the highly oxidative environments, e.g., under water oxidation condition by self-oxidation of nitrogen. ${ }^{164}$ Higashi et al. ${ }^{164}$ showed a modified $\mathrm{TaON}$ with $\mathrm{IrO}_{2}$, which is an excellent OER catalyst, but it could maintain only $50 \%$ of the $J_{\text {int }}$. in less than 10 min (@ 1.2V vs. RHE). Recently, Hou et al. ${ }^{165}$ reported a non-metallic graphitic $\mathrm{C}_{3} \mathrm{~N}_{4}$ coated 3D structured $\mathrm{n}$-TaON with $\mathrm{CoO}_{x}$ co-catalyst that shows significantly enhanced photoelectrochemical stability (3 hours) under OER condition at $\mathrm{pH} 13.6(1 \mathrm{M} \mathrm{NaOH})$. In addition, negative band offsets for both $\mathrm{CB}$ and VB $(-1.0$ $\mathrm{eV}$ and $-0.5 \mathrm{eV}$, respectively) toward the TaON promote an effective charge separation for water oxidation reaction. 3D $\mathrm{WO}_{3} / \mathrm{C}_{3} \mathrm{~N}_{4}$ hetero-junctions decorated with nanoparticle $\mathrm{CoO}_{\mathrm{X}}$ also exhibited enhanced PEC water oxidation performance and stability compared to the unprotected $\mathrm{WO}_{3} .{ }^{166}$ However, the efficiency of the TaON is limited by a wide band-gap that excludes photo-excitation by most of the solar spectrum leading to a maximum theoretical photocurrent of $7.5 \mathrm{~mA} \mathrm{~cm}^{-2}$ based on the Schottky-Queisser limit. ${ }^{167}$ Carbon-based protection layers for high performance low band-gap photoanodes, e.g. Si, can be an appropriate example for comparison with other inorganic protection materials listed previously. Recently, Yoon et al. ${ }^{168}$ coated n-type c-Si with a carbon-based protective multi-layer structure, which is composed of graphene-oxide (GO), single-walled carbon nanotubes, and graphene on top (i.e. n-Si/GO/SWCNT/Graphene) that showed stable water oxidation in $1 \mathrm{M} \mathrm{KOH}(\mathrm{pH} 14)$ for $15 \mathrm{~min}$. This study revealed protection ability of CNT layer for $\mathrm{n}$-Si photoanode for the first time, however, the origin of poor OER kinetics even at relatively high potential ( $0.5 \mathrm{~mA} \mathrm{~cm}^{-2} @ 1.4 \mathrm{~V}$ vs. RHE) was not studied in detail.

\section{Concluding remarks and outlooks}

PEC stability and protection are critically important for the solar-fuel systems to be accepted as a reliable energy system, which can compete with other stability-proven renewable energy sources, such as PV and solar-thermal. Making tandem devices with stable oxide photocatalys ts that have appropriate opto-electronic properties and options where this might not require protective layers (e.g., $\mathrm{Fe}_{2} \mathrm{O}_{3}, \mathrm{BiVO}_{4}$ ) in neutral pH can be a simple solution. However, as shown in the first chapter of this work, it is essential to have protective films 
which can enable the use of technologically well-proven high-performing non-oxide solar cell materials, and development of robust protection thin films has become an emerging research field from early 2010 as demonstrated in Table S1, S2.

So far, various types of protection layer have been evaluated, and among them, $\mathrm{TiO}_{2}$ has been proven for both photocathodes and photoanodes in a wide range of $\mathrm{pH}$ levels from acidic to alkaline, owing to its intrinsic chemical stability. Depending on operating conditions, the $\mathrm{NiO}_{\mathrm{X}}$-family can also be a promising candidate. Particularly, oxidation during OER activity makes the $\mathrm{NiO}_{x}$ a protective layer and efficient OEC layer in the high $\mathrm{pH}$ region. Self-enhancement in overpotential with iron-incorporation and simplicity in fabrication make this strategy attractive. In addition, recent developments with bi-polar membranes, ${ }^{169}$ which can enable the operation of photocathode and photoanode at different $\mathrm{pH}$ conditions, increases degree of freedom in material selection for making full water splitting system.

In addition to this technological development in demonstration of the long-term stable PEC water splitting system, there have also been many scientific studies to understand the fundamentals of charge carrier transport, and to make more efficient PEC system. In this review we introduced representative carrier path mechanisms: electron transport via the conduction band (for photocathodes) and hole - via valence band (for photoanodes), tunneling via very thin insulating oxide, via defect states ('(defect) state-mediated transport' for photoanodes), and via hole-electron recombination at the photoanonde/metal-oxide interface.

Despite significant progress, continued work on protection strategies for PEC systems is needed, particularly, the following aspects should be addressed for practical tandem PEC water splitting system: i) Stability and corrosion in the dark considering day/night operation in practical system; ii) Development of minimally damaging deposition processes for the sensitive PV materials, including, but not limited to organohalide perovskite semiconductors; iii) In-depth studies on new interfaces created by adding protection or other functional layer(s) for minimizing carrier-loss and maximizing photovoltage; iv) The dep endency of OER kinetics on fabrication conditions.

\section{Acknowledgements}

The authors acknowledge the support of the support by VILLUM Center for Science of Susta inable Fuels and Chemicals which is funded from VILLUM Fonden research grant (9455). 
†'Supplementary information available: Supplementary dataset can be found in supporting information parameters for ideal J-V curves in Figure 1; table S1 and S2.

S. Dahl and I. Chorkendorff, Nat. Mater., 2012,11, 100-101.

D. Bae, T. Pedersen, B. Seger, M. Malizia, A. Kuznetsov, O. Hansen, I. Chorkendorff and P. C. K. Vesborg, Energy Environ. Sci., 2015, 8, 650-660.

M. G. Walter, E. L. Warren, J. R. Mckone, S. W. Boettcher, Q. Mi, E. A. Santori and N. S. Lewis, 2010, 6446-6473.

M. S. Burke, L. J. Enman, A. S. Batchellor, S. Zou and S. W. Boettcher, Chem. Mater., 2015, 27, 75497558.

K. Maeda, M. Higashi, D. Lu, R. Abe and K. Domen, J. Am. Chem. Soc., 2010, 132, 5858-5868.

T. Hisatomi, J. Kubota and K. Domen, Chem. Soc. Rev., 2014, 43, 7520-7535.

J. Hofkens and M. Roefaers, Nature, 2016, 530, 36-37.

J. Rongé, T. Bosserez, D. Martel, C. Nervi, L. Boarino, F. Taul elle, G. Decher, S. Bordiga and J. A. Martens, Chem. Soc. Rev., 2014, 43, 7963-7981.

J. Jin, K. Walczak, M. R. Singh, C. Karp, N. S. Lewis and C. Xiang, Energy Environ. Sci. Energy Environ. Sci, 2014, 7, 3371-3371.

B. Seger, I. E. Castelli, P. C. K. Vesborg, K. W. Jacobsen, O. Hansen and I. Chorkendorff, Energy Environ. Sci., 2014, 7, 2397-2413.

R. van de Krol, Photoelectrochemical Hydrogen Production in Electronic Materials: Science \& Technology, ed. R. van de Krol and M. Grätzel, Springer Science + Business Media, Boston, vol. 102, ch. 2, pp. 13-67.

H. S. Park, H. W. Ha, R. S. Ruoff and A. J. Bard, J. Electroanal. Chem., 2014, 716, 8-15.

M. G. Kast, L. J. Enman, N. J. Gurnon, A. Nadarajah and S. W. Boettcher, ACS Appl. Mater. Interfaces, 2014, 6, 22830-22837.

S. Hu, M. R. Shaner, J. a Beardslee, M. Lichterman, B. S. Brunschwig and N. S. Lewis, Science, 2014, 344, 1005-1009.

S. Hilaire, M. J. Suess, N. Kranzlin, K. Bienkowski, R. Solarska, J. Augustynski and M. Niederberger, J. Mater. Chem. A, 2014, 2, 20530-20537.

C. G. Morales-Guio, S. D. Tilley, H. Vrubel, M. Grätzel and X. Hu, Nat. Commun., 2014, 5, 3059.

T. W. Kim and K.-S. K.-S. Choi, Science (80-. )., 2014, 343, 990-994.

L. Zhang, T. Minegishi, M. Nakabayashi, Y. Suzuki, K. Seki, N. Shibata, J. Kubota and K. Domen, Chem. Sci., 2015, 6, 894-901.

A. Standing, S. Assali, L. Gao, M. A. Verheijen, D. van Dam, Y. Cui, P. H. L. Notten, J. E. M. Haverkort and E. P. A. M. Bakkers, Nat. Commun., 2015, 6, 7824.

Gurudayal, D. Sabba, M. H. Kumar, L. H. Wong, J. Barber, M. Grätzel and N. Mathews, Nano Lett., 2015, 15, 3833-3839.

K. Sun, Y. Kuang, E. Verlage, B. S. Brunschwig, C. W. Tu and N. S. Lewis, Adv. Energy Mater., 2015, 5, 1402276.

T. W. Kim, Y. Ping, G. A. Galli and K.-S. Choi, Nat. Commun., 2015, 6, 8769.

Y. Lin, R. Kapadia, J. Yang, M. Zheng, K. Chen, M. Hettick, X. Yin, C. Battaglia, I. D. Sharp, J. W. Ager and A. Javey, J. Phys. Chem. C, 2015, 119, 2308-2313.

D. Bae, B. Mei, R. Frydendal, T. Pedersen, B. Seger, O. Hansen, P. C. K. Vesborg and I. Chorkendorff, ChemElectroChem, 2016, 3, 1546-1552.

B. Seger, O. Hansen, P.C.K. Vesborg, Sol. RRL, 2016, 1600013.

M. M. May, H.-J. Lewerenz, D. Lackner, F. Dimroth and T. Hannappel, Nat. Commun., 2015, 6, 8286.

J. Y. Kim, G. Magesh, D. H. Youn, J.-W. Jang, J. Kubota, K. Domen and J. S. Lee, Sci. Rep., 2013, 3, 2681.

A. J. Bard, J. Photochem., 1979, 10, 59-75.

S. Chen and L.-W. Wang, Chem. Mater., 2012, 24, 3659-3666.

R. Liu, Z. Zheng, J. Spurgeon and X. Yang, Energy Environ. Sci., 2014, 7, 2504-2517.

O. Savadogo, Sol. Energy Mater. Sol. Cells, 1998, 52, 361-388.

K. Walczak, Y. Chen, C. Karp, J. W. Beeman, M. Shaner, J. Spurgeon, I. D. Sharp, X. Amashukeli, W. West, J. Jin, N. S. Lewis and C. Xiang, ChemSusChem, 2015, 8, 544-551. 
N. Takeno, Atlas of Eh-pH diagrams: Intercomposition of thermodynamics database, National Institute of Advanced Industrial Science and Technology, Tokyo, 2005.

D. Bae, S. Shayestehaminzadeh, E. B. Thorsteinsson, T. Pedersen, O. Hansen, B. Seger, P. C. K. Vesborg, S. Ólafsson and I. Chorkendorff, Sol. Energy Mater. Sol. Cells, 2016, 144, 758-765.

J. L. Young, K. X. Steirer, J. Dzara, Michael, J. A. Turner and T. G. Deutsch, J. Mater. Chem. A, 2016, 6, 2831-2836.

A. Q. Contractor and J. O. Bockris, Electrochim. Acta, 1984, 29, 1427-1434.

G. Li and S. Wang, J. Electroanal. Chem. Interfacial Electrochem., 1987, 227, 213-221.

B. Seger, A. B. Laursen, P. C. K. Vesborg, T. Pedersen, O. Hansen, S. Dahl and I. Chorkendorff, Angew. Chemie - Int. Ed., 2012, 51, 9128-9131.

P. A. Kohl, S. N. Frank and A. J. Bard, J. Electrochem. Soc., 1977, 124, 225-229.

A. Paracchino, V. Laporte, K. Sivula, M. Grätzel and E. Thimsen, Nat. Mater., 2011, 10, 456-461.

M. H. Lee, K. Takei, J. Zhang, R. Kapadia, M.Zheng, Y.-Z. Chen, J. Nah, T. S. Matthews, Y.-L. Chueh, J. W. Ager and A. Javey, Angew. Chem. Int. Ed. Engl., 2012, 51, 10760-10764.

B. Seger, S. D. Tilley, T. Pedersen, P. C. K. Vesborg, O. Hansen, M. Graetzel and I. Chorkendorff, RSC Adv., 2013, 3, 25902-25907.

B. Seger, T. Pedersen, A. B. Laursen, P. C. K. Vesborg, O. Hansen and I. Chorkendorff, J. Am. Chem. Soc., 2013, 135, 1057-1064.

Y. W. Chen, J. D. Prange, S. Dühnen, Y. Park, M. Gunji, C. E. D. Chidsey and P. C. Mclntyre, Nat. Mater., 2011, 10, 539-544.

M. R. Shaner, S. Hu, K. Sun and N. S. Lewis, Energy Environ. Sci., 2015, 8, 203-207.

B. Seger, S. D. Tilley, T. Pedersen, P. C. K. Vesborg, O. Hansen, M. Graetzel and I. Chorkendorff, J. Mater. Chem. a, 2013, 1, 15089-15094.

L. Ji, M. D. McDaniel, S. Wang, A. B. Posadas, X. Li, H. Huang, J. C. Lee, A. a Demkov, A. J. Bard, J. G. Ekerdt and E. T. Yu, Nat. Nanotechnol., 2014, 10, 84-90. B. Mei, T. Pedersen, P. Malacrida, D. Bae, R. Frydendal, O. Hansen, P. C. K. Vesborg, B. Seger and I. Chorkendorff, J. Phys. Chem. C, 2015, 119, 15019-15027.

H. D. Abruna and A. J. Bard, J. Am. Chem. Soc., 1981, 103, 6898-6901.

A. Heller and R. G. Vadimsky, Phys. Rev. Lett., 1981, 46, 1153-1156.

A. Heller, E. Aharon-Shalom, W. A. Bonner and B. Miller, J. Am. Chem. Soc., 1982, 104, 6942-6948.

C. Maier, Int. J. Hydrogen Energy, 1996, 21, 859-864.

B. Marsen, B. Cole and E. L. Miller, Sol. Energy Mater. Sol. Cells, 2008, 92, 1054-1058.

D. Yokoyama, T. Minegishi, K. Maeda, M. Katayama, J. Kubota, A. Yamada, M. Konagai and K. Domen, Electrochem. commun., 2010, 12, 851-853.

Y. Hou, B. L. Abrams, P. C. K. Vesborg, M. E. Björketun, K. Herbst, L. Bech, A. M. Setti, C. D. Damsgaard, T. Pedersen, O. Hansen, J. Rossmeisl, S. Dahl, J. K. Nørskov and I. Chorkendorff, Nat. Mater., 2011, 10, 434-438.

A. Paracchino, N. Mathews, T. Hisatomi, M. Stefik, S. D. Tilley and M. Grätzel, Energy Environ. Sci., 2012, 5, 8673-8681.

E. L. Warren, J. R. McKone, H. a. Atwater, H. B. Gray and N. S. Lewis, Energy Environ. Sci., 2012, 5, 96539661.

J. Kim, T. Minegishi, J. Kobota and K. Domen, Energy Environ. Sci., 2012, 5, 6368-6374.

T. Bourgeteau, D. Tondelier, B. Geffroy, R. Brisse, C. Laberty-Robert, S. Campidelli, R. de Bettignies, V. Artero, S. Palacin and B. Jousselme, Energy Environ. Sci., 2013, 6, 2706-2713.

Z. Zhang, R. Dua, L. Zhang, H. Zhu, H. Zhang and P. Wang, ACS Nano, 2013, 7, 1709-1717. Chem. Chem. Phys., 2013, 15, 20000-20004.

Y. Lin, C. Battaglia, M. Boccard, M. Hettick, Z. Yu, C. Ballif, J. W. Ager and A. Javey, Nano Lett., 2013, 13, 5615-5618. and S. Jin, J. Am. Chem. Soc., 2014, 136, 8504-8507. M. J. Choi, J.-Y. Jung, M.-J. Park, J.-W. Song, J.-H. Lee and J. H. Bang, J. Mater. Chem. A, 2014, 2, 29282933.

L. Zhang, T. Minegishi, J. Kubota and K. Domen, Phys. Chem. Chem. Phys., 2014, 16, 6167-6174. 
J. D. Benck, S. C. Lee, K. D. Fong, J. Ki bsgaard, R. Sinclair and T. F. Jaramillo, Adv. Energy Mater., 2014, 4, 1400739.

C. Ros, T. Andreu, S. Giraldo, Y. Sánchez and J. R. Morante, Sol. Energy Mater. Sol. Cells, 2016, 158, 184-188.

J. Feng, M. Gong, M. J. Kenney, J. Z. Wu, B. Zhang, Y. Li and H. Dai, Nano Res., 2015, 8, 1577-1583. A. Azarpira, M. Lublow, A. Steigert, P. Bogdanoff, D. Greiner, C. A. Kaufmann, M. Krüger, U. Gernert, R. Van De Krol, A. Fischer and T. Schedel-Niedrig, Adv. Energy Mater., 2015, 5, 1402148. R. Fan, W. Dong, L. Fang, F. Zheng, X. Su, S. Zou, J. Huang, X. Wang and M. Shen, Appl. Phys. Lett., 2015, 106, 13902. H. Kumagai, T. Minegishi, N. Sato, T. Yamada, J. Kubota and K. Domen, J. Mater. Chem. A, 2015, 3, 8300-8307. I. A. Digdaya, P. P. Rodriguez, M. Ma, G. W. P. Adhyaksa, E. C. Garnett, A. H. M. Smets and W. A. Smith, J. Mater. Chem. A, 2016, 4, 6842-6852. M. Crespo-Quesada, L. M. Pazos-Outón, J. Warnan, M. F. Kuehnel, R. H. Friend and E. Reisner, Nat. Commun., 2016, 7, 12555. Q. Li, M. Zheng, M. Zhong, L. Ma, F. Wang, L. Ma and W. Shen, Sci. Rep., 2016, 6, 29738. F. Urbain, V. Smirnov, J.-P. Becker, A. Lambertz, F. Yang, J. Ziegler, B. Kaiser, W. Jaegermann, U. Rau and F. Finger, Energy Environ. Sci., 2016, 9, 145-154. . Liang, H. Tan, M. Liu, B. Liu, N. Wang, Q. Zhang, Y. Zhao, A. H. M. Smets, M. Zeman and X. Zhang, J. Mater. Chem. A, 2016, 4, 16841-16848. J. Azevedo, S. D. Tilley, M. Schreier, M. Stefik, C. Sousa, J. P. Araújo, A. Mendes, M. Grätzel and M. T. Mayer, Nano Energy, 2016, 24, 10-16. 7, 2044-2049. D. Bae, T. Pedersen, B. Seger, B. Iandolo, O. Hansen, P. C. K. Vesborg and I. Chorkendorff, Catal. Today, 2016, DOI: 10,1016/j.cattod.2016.11.028. O. Khaselev and J. A. Turner, Electrochem. Solid-State Lett., 1999, 2, 310-312. J. R. McKone, A. P. Pieterick, H. B. Gray and N. S. Lewis, J. Am. Chem. Soc., 2013, 135, 223-231. M. Malizia, B. Seger, I. Chorkendorff and P. C. K. Vesborg, J. Mater. Chem. A, 2014, 2, 6847-6853. E. D. Green, M. A; Emery, K.; Hishikawa, Y.; Warta, W.; Dunlop, Prog. Photovolt Res. Appl., 2016, 24, 905-913. R. Fan, W. Dong, L. Fang, F. Zheng, X. Su, S. Zou, J. Huang, X. Wang and M. Shen, Appl. Phys. Lett., 2015, 106, 2-6. J. R. Bakke, K. L. Pickrahn, T. P. Brennan and S. F. Bent, Nanoscale, 2011, 3, 3482-3508.

Press/Taylor \& Francis, Boca Raton, FL, 97th edn., 2016. J. Feng, M. Gong, M. J. Kenney, J. Z. Wu, B. Zhang, Y. Li and H. Dai, Nano Res., 2015, 1, 1-4. A. Azarpira, M. Lublow, A. Steigert, P. Bogdanoff, D. Greiner, C. A. Kaufmann, M. Krüger, U. Gernert, R. Van De Krol, A. Fischer and T. Schedel-Niedrig, Adv. Energy Mater., 2015, 5, 1-9.

2015, 9, 11302-11309. J. D. Benck, T. R. Hellstern, J. Kibsgaard, P. Chakthranont and T. F. Jaramillo, ACS Catal., 2014, 4, 39573971.

P. C. K. Vesborg, B. Seger and I. Chorkendorff, J. Phys. Chem. Lett., 2015, 6, 951-957. T. F. Jaramillo, K. P. Jørgensen, J. Bonde, J. H. Nielsen, S. Horch and I. Chorkendorff, Science, 2007, 317, 100-102.

97 B. Hinnemann, P. G. Moses, J. Bonde, K. P. Jorgensen, J. H. Nielsen, S. Horch, I. Chorkendorff and J. K. Nørskov, J. Am. Chem. Soc., 2005, 127, 5308-5309.

98 D. Merki, S. Fierro, H. Vrubel and X. Hu, Chem. Sci., 2011, 2, 1262-1267.

99 A. G. Scheuermann and P. C. McIntyre, J. Phys. Chem. Lett., 2016, 7, 2867-2878.

100 R. C. Kainthla, J. Electrochem. Soc., 1986, 133, 248-253.

101 R. C. Kainthla, B. Zelenay and J. O. Bockris, J. Electrochem. Soc., 1987, 134, 841-845.

102 S. Y. Reece, J. a. Hamel, K. Sung, T. D. Jarvi, a.J. Esswein, J. J. H. Pijpers and D. G. Nocera, Science (80.)., 2011, 334, 645-648.

103 M. Liao, J. Feng, W. Luo, Z. Wang, J. Zhang, Z. Li, T. Yu and Z. Zou, Adv. Funct. Mater., 2012, 22, 30663074. 
104 K. Sun, N. Park, Z. Sun, J. Zhou, J. Wang, X. Pang, S. Shen, S. Y. Noh, Y. Jing, S. Jin, P. K. L. Yu and D. Wang, Energy Environ. Sci., 2012, 5, 7872-7877.

105 M. J. Kenney, M. Gong, Y. Li, J. Z. Wu, J. Feng, M. Lanza and H. Dai, Science (80-. )., 2013, 342, 836-840.

106 M. F. Lichterman, M. R. Shaner, S. G. Handler, B. S. Brunschwig, H. B. Gray, N. S. Lewis and J. M. Spurgeon, J. Phys. Chem. Lett., 2013, 4, 4188-4191.

107 N. C. Strandwitz, D. J. Comstock, R. L. Grimm, A. C. Nichols-Nielander, J. Elam and N. S. Lewis, J. Phys. Chem. C, 2013, 117, 4931-4936.

108 M. Higashi, K. Domen and R. Abe, J. Am. Chem. Soc., 2013, 135, 10238-10241.

109 K. Sun, X. Pang, S. Shen, X. Qian, J. S. Cheung and D. Wang, Nano Lett., 2013, 13, 2064-2072.

110 B. Mei, A. a Permyakova, R. Frydendal, D. Bae, T. Pedersen, P. Malacrida, O. Hansen, I. E. L. Stephens, P. C. K. Vesborg, B. Seger and I. Chorkendor, J. Phys. Chem. Lett., 2014, 5, 3456-3461.

111 J. Yang, K. Walczak, E. Anzenberg, F. M. Toma, G. Yuan, J. Beeman, A. Schwartzberg, Y. Lin, M. Hettick, A. Javey, J. W. Ager, J. Yano, H. Frei and I. D. Sharp, J. Am. Chem. Soc., 2014, 136, 6191-6194.

112 M. F. Lichterman, A. I. Carim, M. T. McDowell, S. Hu, H. B. Gray, B. S. Brunschwig and N. S. Lewis, Energy Environ. Sci., 2014, 7, 3334-3337.

113 G. Liu, J. Shi, F. Zhang, Z. Chen, J. Han, C. Ding, S. Chen, Z. Wang, H. Han and C. Li, Angew. Chemie - Int. Ed., 2014, 53, 7295-7299.

114 M. T. McDowell, M. F. Lichterman, J. M. Spurgeon, S. Hu, I. D. Sharp, B. S. Brunschwig and N. S. Lewis, J. Phys. Chem. C, 2014, 118, 19618-19624.

115 K. Sun, S. Shen, J. S. Cheung, X. Pang, N. Park, J. Zhou, Y. Hu, Z. Sun, S. Y. Noh, C. T. Riley, P. K. L. Yu, S. Jin and D. Wang, Phys. Chem. Chem. Phys., 2014, 16, 4612-25.

116 E. S. Kim, H. J. Kang, G. Magesh, J. Y. Kim, J. W. Jang and J. S. Lee, ACS Appl. Mater. Interfaces, 2014, 6, 17762-17769.

117 B. Mei, B. Seger, T. Pedersen, M. Malizia, O. Hansen, I. Chorkendorff and P. C. K. Vesborg, J. Phys. Chem. Lett., 2014, 5, 1948-1952.

118 X. Shi, I. Y. Choi, K. Zhang, J. Kwon, D. Y. Kim, J. K. Lee, S. H. Oh, J. K. Kim and J. H. Park, Nat. Commun., $2014,5,4775$.

119 K. Sun, M. T. McDowell, A. C. Nielander, S. Hu, M. R. Shaner, F. Yang, B. S. Brunschwig and N. S. Lewis, J. Phys. Chem. Lett., 2015, 6, 592-598.

120 K. Sun, F. H. Saadi, M. F. Lichterman, W. G. Hale, H.-P. Wang, X. Zhou, N. T. Plymale, S. T. Omelchenko, J.-H. He, K. M. Papadantonakis, B.S. Brunschwig and N. S. Lewis, Proc. Natl. Acad. Sci. , 2015, 112, 3612-3617.

121 M. T. McDowell, M. F. Lichterman, A. I. Carim, R. Liu, S. Hu, B. S. Brunschwig and N. S. Lewis, ACS Appl. Mater. Interfaces, 2015, 7, 15189-15199.

122 X. Zhou, R. Liu, K. Sun, D. Friedrich, M. T. McDowell, F. Yang, S. T. Omelchenko, F. H. Saadi, A. C. Nielander, S. Yalamanchili, K. M. Papadantonakis, B. S. Brunschwig and N. Lewis, Energy Environ. Sci., 2015, 8, 2644-2649.

123 L. Chen, J. Yang, S. Klaus, L. J. Lee, R. Woods-Robinson, J. Ma, Y. Lum, J. K. Cooper, F. M. Toma, L. W. Wang, I. D. Sharp, A. T. Bell and J. W. Ager, J. Am. Chem. Soc., 2015, 137, 9595-9603.

124 C. Li, T. Wang, Z. Luo, D. Zhang and J. Gong, Chem. Commun., 2015, 51, 7290-7293.

125 M. Zhong, T. Hisatomi, Y. Kuang, J. Zhao, M. Liu, A. Iwase, Q. Jia, H. Nishiyama, T. Minegishi, M. Nakabayashi, N. Shibata, R. Niishiro, C. Katayama, H. Shibano, M. Katayama, A. Kudo, T. Yamada and K. Domen, J. Am. Chem. Soc., 2015, 137, 5053-5060.

126 W. Li, S. W. Sheehan, D. He, Y. He, X. Yao, R. L. Grimm, G. W. Brudvig and D. Wang, Angew. Chemie - Int. Ed., 2015, 54, 11428-11432.

127 J. H. Kim, Y. Jo, J. H. Kim, J. W. Jang, H. J. Kang, Y. H. Lee, D. S. Kim, Y. Jun, J. S. Lee and K. I. M. E. T. Al, ACS Nano, 2015, 9, 11820-11829.

128 I. Narkeviciute, P. Chakthranont, A. J. M. Mackus, C. Hahn, B. A. Pinaud, S. F. Bent and T. F. Jaramillo, Nano Lett., 2016, 16, 7565-7572.

129 M. Sarnowska, K. Bienkowski, P. J. Barczuk, R. Solarska and J. Augustynski, Adv. Energy Mater., 2016, 6, $1-6$.

130 S. Akiyama, M. Nakabayashi, N. Shibata, T. Minegishi, Y. Asakura, M. Abdulla-Al-Mamun, T. Hisatomi, H. Nishiyama, M. Katayama, T. Yamada and K. Domen, Small, 2016, 12, 5468-5476.

131 W. L. Kwong, C. C. Lee and J. Messinger, J. Phys. Chem. C, 2016, 120, 10941-10950.

132 T. Yao, R. Chen, J. Li, J. Han, W. Qin, H. Wang, J. Shi, F. Fan and C. Li, J. Am. Chem. Soc., 2016, 138, 13664-13672.

133 E. S. Kim, N. Nishimura, G. Magesh, J. Y. Kim, J. Jang, H. Jun, J. Kubota, K. Domen and J. S. Lee, J. Am. 
Chem. Soc., 2013, 135, 5375-5383.

134 J. M. Spurgeon, J. M. Velazquez and M. T. McDowell, Phys. Chem. Chem. Phys., 2014, 16, 3623-3631.

135 S. Cherevko, S. Geiger, O. Kasian, N. Kulyk, J. P. Grote, A. Savan, B. R. Shrestha, S. Merzlikin, B. Breitbach, A. Ludwig and K. J. J. Mayrhofer, Catal. Today, 2016, 262, 170-180.

136 S. Bai, M. Cao, Y. Jin, X. Dai, X. Liang, Z. Ye, M. Li, J. Cheng, X. Xiao, Z. Wu, Z. Xia, B. Sun, E. Wang, Y. Mo, F. Gao and F. Zhang, Adv. Energy Mater., 2014, 4, 1-6.

137 M. D. Irwin, D. B. Buchholz, A. W. Hains, R. P. H. Chang and T. J. Marks, Proc. Natl. Acad. Sci., 2008, 105, 2783-2787.

138 E. Nurlaela, H. Wang, T. Shinagawa, S. Flanagan, S. Ould-Chikh, M. Qureshi,Z. Mics, P. Sautet, T. Le Bahers, E. Cánovas, M. Bonn and K. Takanabe, ACS Catal., 2016, 6, 4117-4126.

139 L. Trotochaud, S. L. Young, J. K. Ranney and S. W. Boettcher, J. Am. Chem. Soc., 2014, 136, 6744-6753.

140 M. S. Burke, M. G. Kast, L. Trotochaud, A. M. Smith and S. W. Boettcher, J. Am. Chem. Soc., 2015, 137, 3638-3648.

141 G. Li and S. Wang, J. Electroanal. Chem. Interfacial Electrochem., 1987, 227, 213-221.

142 H. Sato, T. Minami, S. Takata and T. Yamada, Thin Solid Films, 1993, 236, 27-31.

143 B. A. Nail, J. M. Fields, J. Zhao, J. Wang, M. J. Greaney, R. L. Brutchey and F. E. Osterloh, ACS Nano, $2015,5135-5142$.

144 Y. Jiang, X. Li, T. Wang and C. Wang, Nanoscale, 2016, 9667-9675.

145 C.-W. Tung, Y.-Y. Hsu, Y.-P. Shen, Y. Zheng, T.-S. Chan, H.-S. Sheu, Y.-C. Cheng and H. M. Chen, Nat. Commun., 2015, 6, 8106.

146 M. Tomkiewicz and J. M. Woodall, J. Electrochem. Soc., 1977, 124, 1436.

147 J. Nelson and R. E. Chandler, Coord. Chem. Rev., 2004, 248, 1181-1194.

148 A. G. Scheuermann, J. D. Prange, M. Gunji, C. E. D. Chidsey and P. C. Mclntyre, Energy Environ. Sci., 2013, 6, 2487-2496.

149 A. G. Scheuermann, J. P. Lawrence, K. W. Kemp, T. Ito, A. Walsh, C. E. D. Chidsey, P. K. Hurley and P. C. McIntyre, Nat. Mater., 2016, 15, 99-105.

150 U. K. Kirner, K. D. Schierbaum and W. Göpel, Fresenius. J. Anal. Chem., 1991, 341, 416-420.

151 M. Cerchez, H. Langer, M. El Achhab, T. Heinzel, D. Ostermann, H. Lüder and J. Degenhardt, Appl. Phys. Lett., 2013, 103, 033522.

152 W. De Bosscher, R. Van Meirhaeghe, A. De Laere, W. Laflere and F. Cardon, Solid. State. Electron., 1988, 31, 1629-1634.

153 R. T. Tung, Appl. Phys. Lett., 1991, 58, 2821-2823.

154 R. T. Tung, Phys. Rev. B, 1992, 45, 13509-13523.

155 R. C. Rossi and N. S. Lewis, J. Phys. Chem. B, 2001, 105, 12303-12318.

156 J. C. Hill, A. T. Landers and J. a Switzer, Nat Mater, 2015, 14, 1150-1155.

157 E. Kemppainen, A. Bodin, B. Sebok, T. Pedersen, B. Seger, B. Mei, D. Bae, P. C. K. Vesborg, J. Halme, O. Hansen, P. D. Lund and I. Chorkendorff, Energy Environ. Sci., 2015, 8, 2991-2999.

158 S. Hu, M. H. Richter, M. F. Lichterman, J. Beardslee, T. Mayer, B. S. Brunschwig and N. S. Lewis, J. Phys. Chem. C, 2016, 120, 3117-3129.

159 G. Man, J. Schwartz, J. C. Sturm and A. Kahn, Adv. Mater. Interfaces, 2016, 3, 1-8.

160 H. H. Pham and L.-W. Wang, Phys. Chem. Chem. Phys., 2015, 17, 541-550.

161 P. Reckers, M. Dimamay, J. Klett, S. Trost, K. Zilberberg, T. Riedl, B. A. Parkinson, J. Brötz, W. Jaegermann and T. Mayer, J. Phys. Chem. C, 2015, 119, 9890-9898.

162 H. J. Lewerenz, J. Electrochem. Soc., 2014, 161, H3117-H3129.

163 W. Chun, A. Ishikawa, H. Fujisawa, T. Takata, J. N. Kondo, M. Hara, M. Kawai, Y. Matsumoto and K. Domen, J. Phys. Chem. B, 2003, 107, 1798-1803.

164 M. Higashi, K. Domen and R. Abe, J. Am. Chem. Soc., 2012, 134, 6968-6971.

165 J. Hou, H. Cheng, O. Takeda and H. Zhu, Energy Environ. Sci., 2015, 8, 1348-1357.

166 Y. Hou, F. Zuo, A. P. Dagg, J. Liu and P. Feng, Adv. Mater., 2014, 26, 5043-5049.

167 W. Shockley and H. J. Queisser, J. Appl. Phys., 1961, 32, 510-519.

168 K. Yoon, J.-H. Lee, J. Kang, J. Kang, M. J. Moody, M. C. Hersamand L. J. Lauhon, Nano Lett., 2016, 16, 7370-7375.

169 J. Luo, D.A. Vermaas, D. Bi, A. Hagfeldt, W.A. Smith, M. Grätzel, Adv. Energy Mater., 2016, 6, 1600100. 
Dowon Bae received his BSc. and MSc. (Honors) from Russian State Technological University named after K.E. Tsiolkovsky in 2006 and 2008, respectively. After the research activities in $\mathrm{Cu}(\mathrm{In}, \mathrm{Ga}) \mathrm{Se}_{2}$ solar cell at the LG Innotek, he joined the Danish National Research Foundation "CINF" (Center for Individual Nanoparticle Functionality) at the Technical University of Denmark (DTU), where he completed his PhD in 2012 under supervision by Prof. Ib Chorkendorff. Presently, he is a postdoctoral researcher of the VILLUM Center for the Science of Sustainable Fuels and Chemicals at the DTU Physics. His research concerns PEC device design and fabrication for solar-fuel production.

Prof. Brian Seger completed his Ph.D. from Notre Dame under Prof. Prashant Kamat in 2009. He has since completed postdocs at the University of Queensland under Lian Zhou Wang and he joined the "CINF" at DTU under Prof. Ib Chorkendorff. Since 2014, he has been an assistant professor at DTU Physics. His research interests include understanding semiconductor-electrolyte interfaces, discovering new photoactive materials, and modeling photoelectrochemical devices.

Peter C. K. Vesborg received his Ph.D. degree in Applied Physics from the DTU in 2010. He then went to the department of Chemical Engineering at Stanford University as a postdoc under Prof. Thomas Jaramillo before returning to DTU to join the faculty of the department of Physics in 2012, where he has been associate professor since 2015. His research concerns catalysis (thermal, electro-, and photocatalysis), photoelectrodes, MEMS-based device development for catalyst benchmarking, and gl obal resource availability and management for sustainable technologies.

Prof. Ole Hansen received the MSc. degree in micro-technology from the DTU in 1977. Since 1977 he has worked with micro- and nano-technology and applications of the technology within electronics, metrology, sensing, catalysis and energy harvesting. Currently, he is Professor at DTU Nanotech, where he is heading the Silicon Microtechnology group. Current research interests include sustainable energy, photocatalysis and tools for characterizing catalytic processes. From 2005-2016 he was part of the 'CINF', and presently, he is part of ' $V$ SUSTAIN' (VILLUM Center for the Science of Sustainable Fuels and Chemicals).

Prof. Ib Chorkendorff got his PhD from Odense University (1985). After working as a post-doc with Prof. John T. Yates Jr. at University of Pittsburgh, he was employed at DTU (1987) to establish an experimental activity, investigating fundamental aspects of heterogeneous catalysis. He was Director of the 'CINF' (2005-2016) and subsequent Director of the 'V-SUSTAIN'. He has been author of close to 300 scientific papers and 17 patents. His research activities focus on surface reactions and finding new materials to improve energy production/conversion and environmental protection. He is co-founder of start-up companies RENCAT APS, HPNOW APS and Spectroinlets APS. 
This review provides a comprehensive overview of the key aspects of protection strategies for achieving stable solid/liquid interfaces for photoelectrodes.
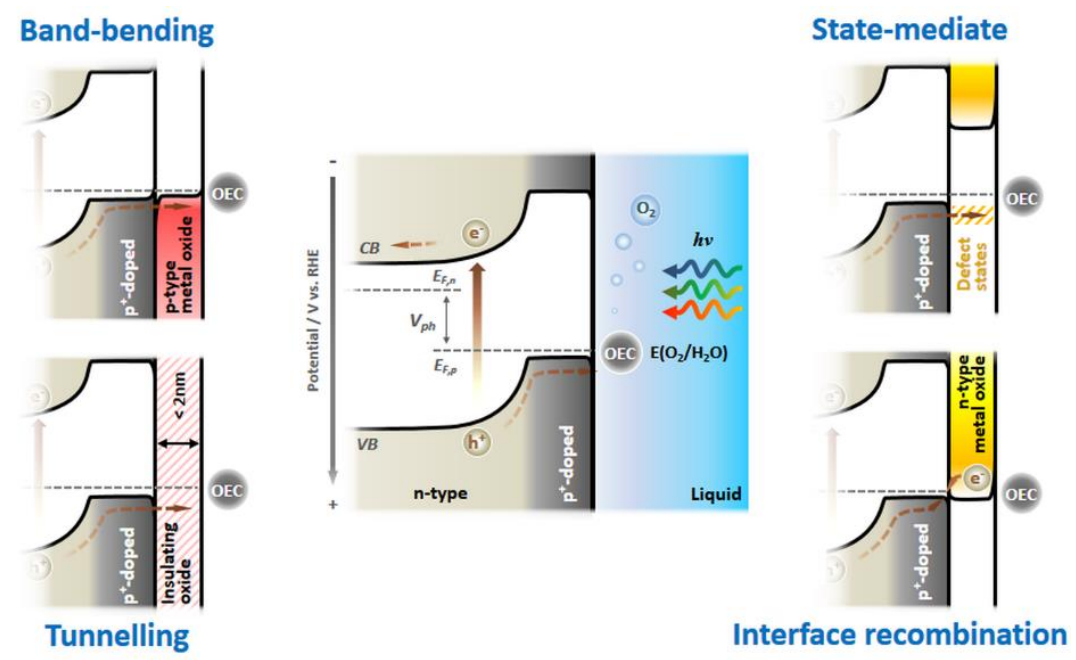